Florida International University

FIU Digital Commons

\title{
Stakeholder Value Dynamics Analysis in Hurricane Michael: Towards Collaborative Decision Making in Building Disaster Resilient Communities
}

Aishwarya Pathak

apath002@fiu.edu

Follow this and additional works at: https://digitalcommons.fiu.edu/etd

Part of the Community-Based Research Commons, Construction Engineering and Management Commons, Other Social and Behavioral Sciences Commons, and the Work, Economy and Organizations Commons

\section{Recommended Citation}

Pathak, Aishwarya, "Stakeholder Value Dynamics Analysis in Hurricane Michael: Towards Collaborative Decision Making in Building Disaster Resilient Communities" (2020). FIU Electronic Theses and Dissertations. 4387.

https://digitalcommons.fiu.edu/etd/4387

This work is brought to you for free and open access by the University Graduate School at FIU Digital Commons. It has been accepted for inclusion in FIU Electronic Theses and Dissertations by an authorized administrator of FIU Digital Commons. For more information, please contact dcc@fiu.edu. 


\title{
FLORIDA INTERNATIONAL UNIVERSITY \\ Miami, Florida
}

\section{STAKEHOLDER VALUE DYNAMICS ANALYSIS IN HURRICANE MICHAEL: TOWARDS COLLABORATIVE DECISION MAKING IN BUILDING DISASTER RESILIENT COMMUNITIES}

\author{
A thesis submitted in partial fulfillment of \\ the requirements for the degree of \\ MASTER OF SCIENCE \\ in \\ CONSTRUCTION MANAGEMENT \\ by \\ Aishwarya Shrikant Pathak
}


To: Dean John L. Volakis

College of Engineering and Computing

This thesis, written by Aishwarya Shrikant Pathak, and entitled Stakeholder Value Dynamics Analysis in Hurricane Michael: Towards Collaborative Decision Making in Building Disaster Resilient Communities, having been approved in respect to style and intellectual content, is referred to you for judgement.

We have read this thesis and recommend that it is approved.

Nipesh Pradhananga

Emel Ganapati

Lu Zhang, Major Professor

Date of Defense: March 27,2020

The thesis of Aishwarya Shrikant Pathak is approved.

Dean John L. Volakis

College of Engineering and Computing

Andres G. Gill

Vice President for Research and Economic Development and Dean of the University Graduate School

Florida International University, 2020 
(C) Copyright 2020 by Aishwarya Shrikant Pathak

All rights reserved. 


\section{DEDICATION}

This thesis is dedicated to my loving parents and my husband.

Without you, none of my success would be possible. 


\section{ACKNOWLEDGMENTS}

I would like to extend my sincere gratitude to my major advisor Professor Lu Zhang for her continuous guidance and support during my masters' program. I am proud and honoured to have had the privilege of completing my master's degree under her guidance and supervision. I appreciate her vast knowledge and skills in many areas (e.g., value theory, community resilience), her passion in these fields of study has always been an inspiration. This thesis would not have been possible without her supervision and direction.

I would also like to deeply thank my Thesis Committee Members - Prof. Nipesh Pradhananaga and Prof. N. Emel Ganapati for their guidance, encouragement, insightful comments and advice during my research and for finding time in their busy schedule for my defense.

I would like to give special thanks to my husband, Kapil Mahajan, for his love, understanding, and support. Thank him for encouraging me in all my pursuits and for inspiring me to follow my dreams. Special thanks also go to my parents and the rest of my family for your endless support and for always being there for me. A sincere thanks to all my friends and colleagues who have kept supporting me throughout my graduate study. Their influence on my learning process is worth mentioning.

Finally, I gratefully acknowledge the funding support of the Natural Hazards Center and National Science Foundation. 
ABSTRACT OF THE THESIS

STAKEHOLDER VALUE DYNAMICS ANALYSIS IN HURRICANE MICHAEL:

TOWARDS COLLABORATIVE DECISION MAKING IN BUILDING DISASTER

RESILIENT COMMUNITIES

by

Aishwarya Shrikant Pathak

Florida International University, 2020

Miami, Florida

Professor Lu Zhang, Major Professor

Despite a growing acknowledgement of shared responsibilities in emergency management, one of the hidden and overlooked issues in the disaster literature is the identification and integration of multi-sector stakeholder values: the things that are of importance, merit, and utilities to the stakeholders. Stakeholders (e.g., public, private and the non-profit sectors, and the communities) hold numerous values with varying degrees of importance, forming a system of value priorities. Stakeholder values and value priorities - referred to as value systems - are not static in a disaster context; they are dynamic, time-sensitive and event-driven. A more in-depth understanding of the dynamics of stakeholder value systems is crucial to facilitate the policy makers to introduce more pro-active and timely measures towards building resilient communities. To address this gap, this thesis focuses on identifying and understanding the stakeholder values across different disaster phases in the context of Hurricane Michael. Based mainly on semistructured interviews with 51 stakeholders in Hurricane Michael affected areas in Florida, sixteen stakeholder values were identified and classified into four broad categories of 
Schwartz's Theory of Basic Human Values: conservation, openness to change, selftranscendence, and self-enhancement value categories. Despite different value priorities of stakeholders, some of the most prioritized values include safety, resource efficiency, community adaptability, community cohesion, and community growth. The results also show that although these is a general consensus on the importance of the identified values, different stakeholders have different value priorities. In addition, the importance of stakeholder values dynamically changes across different disaster phases (i.e., preparedness, response, recovery, mitigation). The study's findings inform practitioners about implementing disaster resilience strategies that account for diverse stakeholder needs and priorities, thus facilitating human-centered decision making in emergency management. 


\section{TABLE OF CONTENTS}

CHAPTER

PAGE

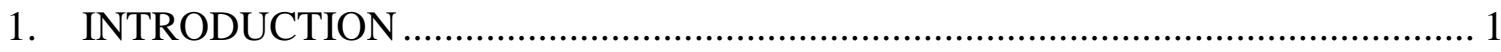

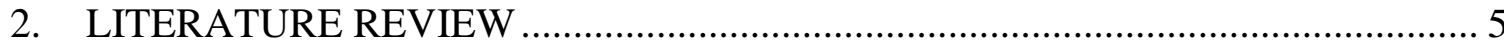

2.1.Human Values......................................................................................... 5

2.2. Schwartz's Theory of Basic Human Values ........................................................ 7

2.3. Collaborative Decision Making for Disaster Management ................................ 11

2.4. State of the Art and Knowledge Gaps in Disaster Literature.............................. 12

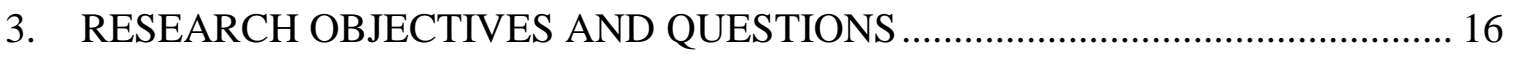

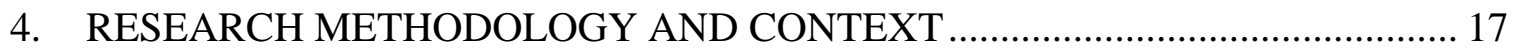

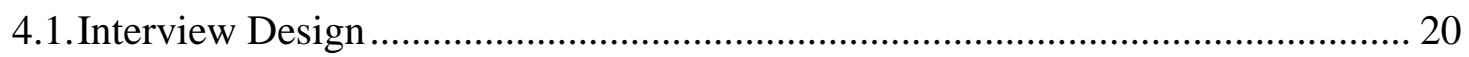

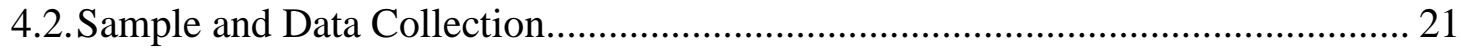

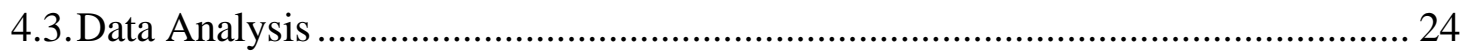

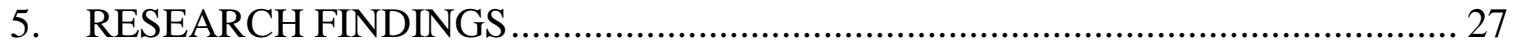

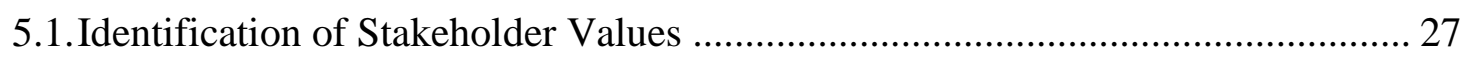

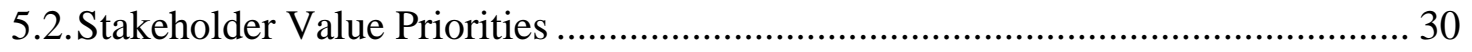

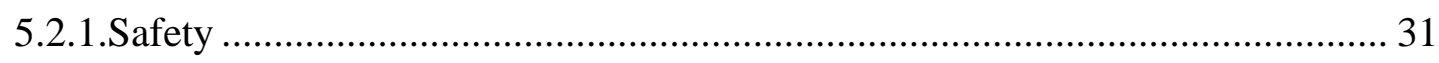

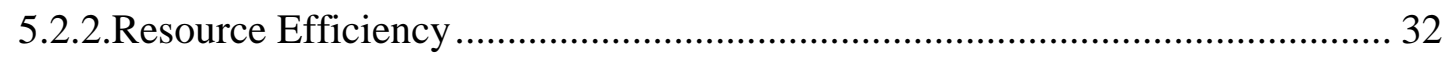

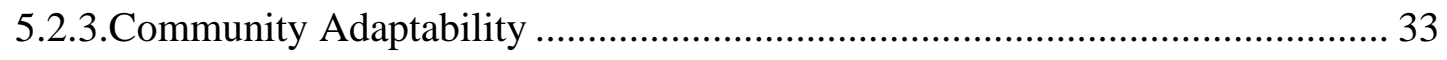

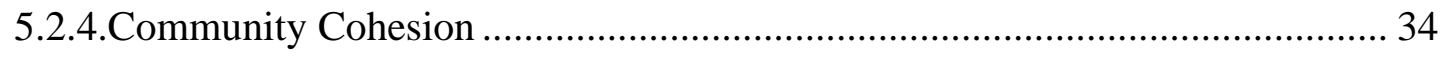

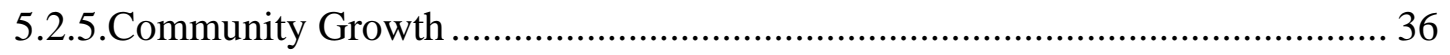

5.3. Stakeholder Value Priorities Across Sectors: Similarities and Differences .......... 37

5.4. Stakeholder Value Dynamics: Comparison Across Disaster Phases .................... 43

6. RECOMMENDATIONS FOR IMPROVING DISASTER RESILIENCE

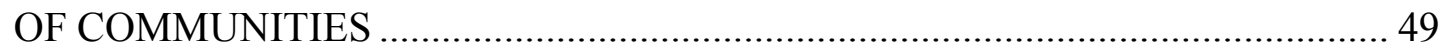

7. CONCLUSIONS, CONTRIBUTIONS, AND FUTURE WORK ............................ 52

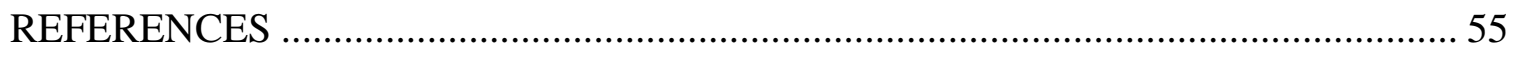

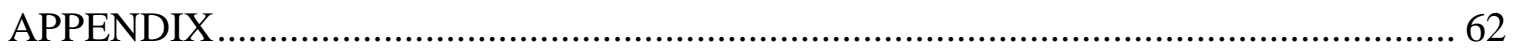




\section{LIST OF TABLES}

TABLE

PAGE

Table 1: Examples of Application of Schwartz's theory of Basic Human Values ............ 7

Table 2: Schwartz's Ten Basic Human Values (Schwartz, 2012) ................................. 10

Table 3: Demographic Information of the Interviewees............................................... 22

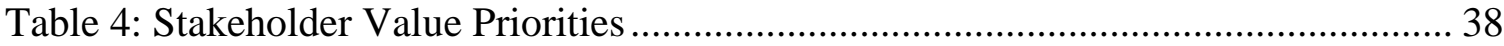




\section{LIST OF FIGURES}

FIGURES

PAGE

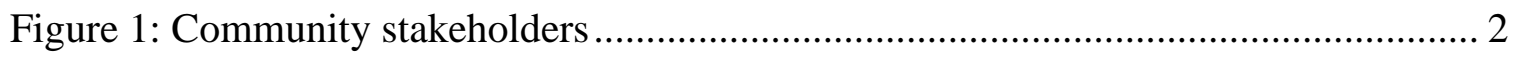

Figure 2: Timeline of Research on Human Values.................................................. 6

Figure 3: Schwartz's value framework (Schwartz 2012) ........................................... 9

Figure 4: Housing destructions caused by Hurricane Michael in Panama City ............... 17

Figure 5 : Track map of Hurricane Michael \& the counties affected (FEMA 2018) ....... 19

Figure 6: The coding of interview data based on Value using NVivo........................... 25

Figure 7: The coding of interview data based on Disaster phases using NVivo ............. 25

Figure 8: The coding of interview data based on Stakeholders using NVivo ................. 26

Figure 9: Identified stakeholder values in the context of Hurricane Michael.................. 27

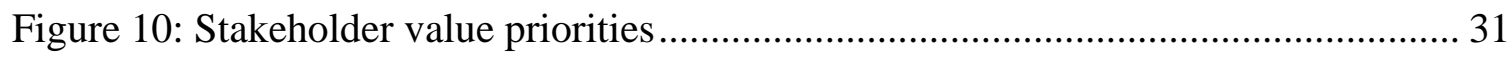

Figure 11: Stakeholder value priorities across different sectors ................................ 39

Figure 12: Stakeholder value dynamics in Hurricane Michael .................................... 43 


\author{
ABBREVATIONS AND ACRONYMS \\ FEMA - Federal Emergency Management Agency \\ NOAA - National Oceanic and Atmospheric Administration \\ NGO - Non-government organization \\ SVS - Schwartz Value Survey \\ PVQ - Portrait Value Questionnaire
}




\section{INTRODUCTION}

"The work of the emergency management does not belong just to FEMA. It is the responsibility of the whole community, federal, [state and local governments], private sector partners, and private citizens to build collective capacity and prepare for the disasters we will inevitably face.", as noted by FEMA in its 2017 Hurricane Season After Action Report (FEMA 2018, p. 50). Strengthening partnerships among multi-sector stakeholders is one of the fundamental strategies to transform the way we prepare for, respond to, and recover from increasingly severe weather events. In the 2018 hurricane season, fifteen named storms, eight hurricanes, and two major hurricanes caused a total of over $\$ 50.2$ billion in damage. The 2018 hurricane season has thus become the third in a consecutive series of above average and active Atlantic hurricane seasons (NOAA 2018). Given this context, the Federal Emergency Management Agency (FEMA), as well as other emergency management agencies and resilience offices, have been calling for the need to thoroughly engage multi-sector stakeholders in a collaborative effort to build more resilient communities.

Despite the broader acknowledgment of shared responsibilities in emergency management, one of the hidden and overlooked issues in disaster literature is the identification and integration of multi-sector stakeholder values: things that are of importance, merit, and utility to stakeholders (Zhang and El-Gohary 2016) (e.g., life safety to community residents, profitability to home developers, system integrity to engineers, and electability to elected officials). Stakeholders are individuals who are either involved in different phases of disaster management or simply impacted by a disaster. These stakeholders can be from different levels of government, the private sector, the non- 
government organizations (NGOs), and community residents. Figure 1 shows different types of stakeholders. Different stakeholders have different values with varying degree of importance, which form a system of value priorities (Zhang and El-Gohary 2016). Stakeholder values and value priorities, referred to as value systems, drive and motivate stakeholders' actions and decisions throughout different phases (e.g., preparedness, response, recovery, mitigation) of a disaster.

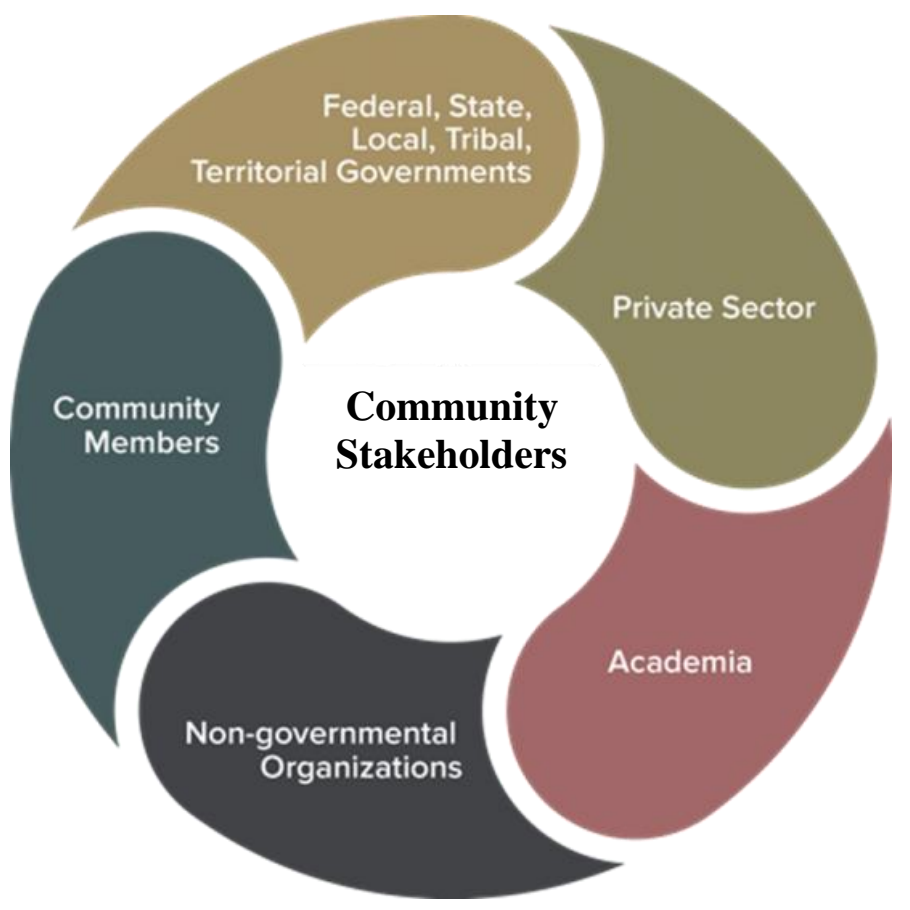

Figure 1: Community stakeholders

Stakeholder value systems are not static in the context of a disaster; they are dynamic, time-sensitive and event-driven. Research shows that major life events could impact individuals' value systems (Bardi et al. 2014; Tormos et al. 2017). Disasters, as a devastating experience to most of the impacted people, could potentially alter people's value systems. Stakeholder value priorities could change throughout different disaster phases. Having a comprehensive and deep understanding of stakeholder value systems and 
how they dynamically change in each disaster phase is crucial as stakeholder value systems motivate and orient decision-making processes (Cheng and Fleischmann 2010). A more in-depth understanding of stakeholder value systems allows decision makers to implement different strategies and practices in a way that addresses stakeholders' prioritized concerns and needs in a time-sensitive manner.

Despite the importance of stakeholder values, there is a lack of empirical studies that explicitly and systematically identify and analyze them in a disaster context. There is also limited research that examines how stakeholder value systems change in the aftermath of disasters or with the time elapsing after disasters. Many existing research efforts have emphasized the importance of engaging multi-sector stakeholders in disaster management and proposed strategies for facilitating stakeholder engagement (e.g., Ganapati and Ganapati 2009; Ganapati and Mukherji 2014; Kapucu and Garayev 2011; Kapucu and Van Mart 2006). Although the underlying goal of stakeholder engagement is to account for their diverse values in decision making, these efforts have neither explicitly nor systematically captured stakeholder value systems. In addition, during a disastrous event, stakeholders may have an entirely different set of value priorities, compared with their original value priorities in non-disaster time. Existing research has mainly focused on examining socioeconomic or demographic variables (e.g., gender, poverty, unemployment) as antecedents of individuals' value priorities (Hitlin and Piliavin 2004; Schwartz 2004). However, contextual variables (e.g., the disaster context) may be just as important as understanding the value priorities and their potential changes over time.

To address the above-mentioned gaps, this study aims to understand the dynamics of multi-sector stakeholder value systems in the context of 2018 Hurricane Michael. Based 
on semi-structured interviews with 51 stakeholders from public sector, private sector, NGOs, and community residents and review of secondary sources in hurricane affected areas, it identifies what different stakeholders value in affected areas and classifies these values according to Schwartz's Theory of Basic Human Values (Schwartz 2012). It then compares the value priorities across different sectors and examines how stakeholders' value systems have changed throughout different phases of Hurricane Michael.

The remainder of the thesis provides summarizes the knowledge gaps, presents research objectives and questions, explains the methodology and the research background, discusses about results and findings, and concludes with a summary and contributions. 


\section{LITERATURE REVIEW}

\subsection{Human Values}

Human Values are goals of individuals that guide their behaviors (Schwartz 1992; Fischer 2017). In social science domain, a number of theories (Fig. 2) have been developed on human values over the last century. For example, Spranger (1921) proposed the first value model that focuses on classifying different value orientations based on different types of people. He proposed that at least one of six value orientations (theoretical, economic, aesthetic, social, political, and religious) are predominant for each type of people. Allport et al. (1960) then studied different value possessed by the different types of people by designing a survey to measure these six types of value orientations. However, Allport et al. (1960)'s value theory was disagreed by Milton Rokeach (1971). He categorized and ranked the values based on people's "beliefs and attitudes" and their importance. He proposed two sets of values, terminal values (goals that a person would like to achieve during his or her lifetime) and instrumental values (modes of behavior). He proposed a total of 36 values and classified them under these two sets. For example, "equality", "wisdom", and "selfrespect" are terminal values, while "obedient", "courage", and "ambition" are instrumental values (Rokeach 1971). 


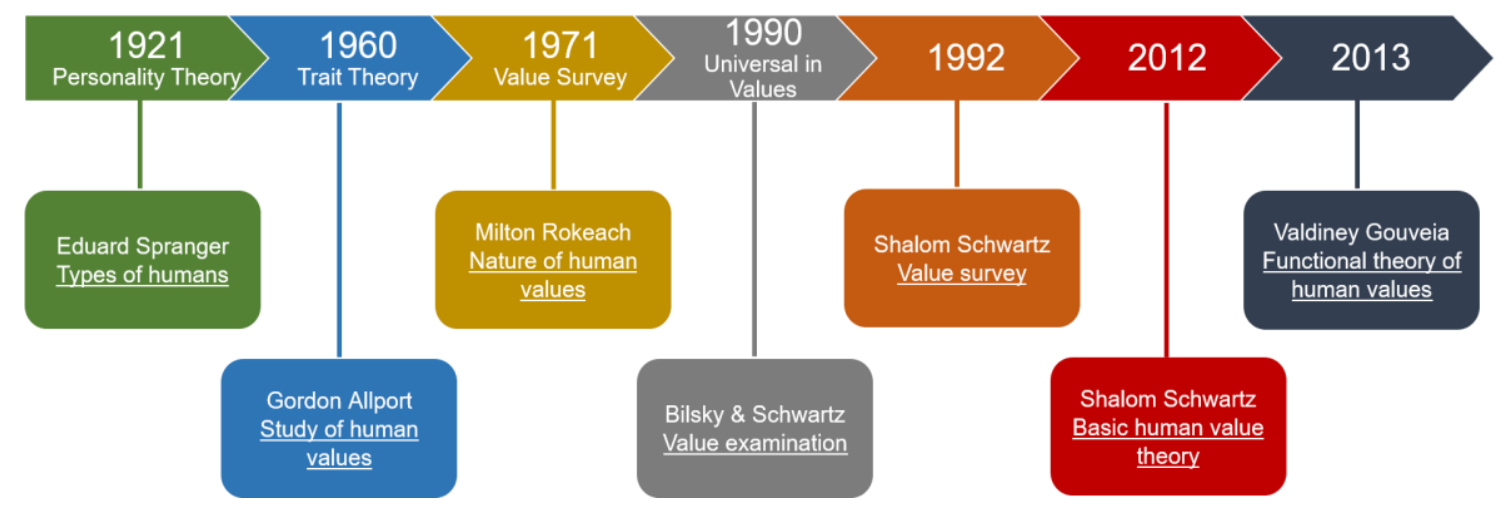

Figure 2: Timeline of Research on Human Values

Although Rokeach's theory was highly influential, it lacked a way of making predications regarding the connections among various values. This theory was further examined by Bilsky and Schwartz (Schwartz and Bilsky 1990). Bilsky and Schwartz (Schwartz and Bilsky 1990) found that the 36 values from the Rokeach's theory can be further categorized into seven or eight value categories based on their motivational dynamics, and they can be further classified into two dimensions. Based on the Rokeach theory and further research conducted by Bilsky and Schwartz, Schwartz formulated the Schwartz's theory of basic human values (Schwartz 1992). Schwartz's theory was validated using various measures and methods (Schwartz 1992). For example, Schwartz developed an instrument called as 'Schwartz Value Survey'(SVS) to rate the importance of the values included in his theory, and he also developed an alternative to SVS, which is the Portrait Value Questionnaire (PVQ) to rate the importance of the ten basic values in his theory. Following Schwartz's work, one of the most recent value theories was proposed by Gouveia (2013). Gouveia (2013) proposed a functional theory of human values. This theory is established by integrating Maslow's hierarchy of needs, and it proposes two functions of values (i.e., values as expressions of needs), including thriving needs (e.g., 
excitement values such as emotions, suprapersonal values such as beauty, interactive values such as affection) and survival needs (e.g., promotion values such as power, existence values such as health, normative values such as obedience). However, Gouveia's theory was challenged by Schwartz (2014), as it lacked originality (Schwartz 2014). For this thesis, Schwartz's theory of Basic Human Values is selected because it is "one of the most commonly used and tested transcultural theories in the field of behavioral research, with numerous validations" (Giménez \& Tamajón 2019). Table 1 summarizes some examples where Schwartz theory of basic human values were applied or used for analysis.

Table 1: Examples of Application of Schwartz's theory of Basic Human Values

\begin{tabular}{|l|l|}
\hline \multicolumn{1}{|c|}{ Research } & \multicolumn{1}{|c|}{ Descriptions } \\
\hline Cohen (2009) & $\begin{array}{l}\text { Schwartz's theory was applied to examine values of } \\
\text { diverse groups, ranging from high tech employees to high } \\
\text { profile businessmen. }\end{array}$ \\
\hline Lyons et al. (2006) & $\begin{array}{l}\text { Schwartz's theory was applied to examine values of } \\
\text { knowledge workers. }\end{array}$ \\
\hline Cohen and Shamai (2010) & $\begin{array}{l}\text { Schwartz's theory was applied to examine values of police } \\
\text { officers. }\end{array}$ \\
\hline Ariza-Montes et al. (2017) & $\begin{array}{l}\text { Schwartz's theory was applied to examine values of } \\
\text { hospitality employees. }\end{array}$ \\
\hline Lyons et al. (2006) & $\begin{array}{l}\text { Comparison of values across various sectors based on } \\
\text { Schwartz's theory. }\end{array}$ \\
\hline
\end{tabular}

\subsection{Schwartz's Theory of Basic Human Values}

Schwartz (2012) developed the Theory of Basic Human Values in the context of intercultural research. This theory aims to measure universal values that are recognized throughout people from different cultural backgrounds. According to this theory, values are the things that are of importance to stakeholders. Each stakeholder holds numerous values (e.g., achievement, security, benevolence) with varying degrees of importance. A specific value may be very important to one stakeholder but unimportant to another. The 
theory has three main features (Schwartz 2012): (1) Values refer to desirable goals that motivate actions and decision-making processes. For example, a community resident who values the property's safety would install hurricane shutters prior to a disaster; (2) Multiple values are ordered by importance relative to one another to form a system of value priorities. Different people have different systems of value priorities. For example, in the context of disasters, a businessman may value safety over business development; and (3) Multiple values guide action - the tradeoffs among relevant but competing values guide actions and decision-making processes. For example, a community resident may value both property safety and renovation cost savings. He/she may need to make a tradeoff when deciding whether to install expensive high-impact windows or more affordable hurricane shutters.

Schwartz's theory identifies ten basic human values, including self-direction, stimulation, hedonism, achievement, power, security, conformity, tradition, benevolence and universalism (Schwartz 2012). These ten values are universal because they are grounded in three common requirements of human existence, including needs of individuals as biological organisms, requisites of coordinated social interaction, and survival and welfare needs of groups. They are further grouped into two bipolar dimensions with four main categories: self-transcendence, self-enhancement, conservation, and openness to change. The first-dimension contrasts "self-enhancement" and "selftranscendence" values; it captures the conflicts or synergies between: (1) values that emphasize the pursuit of one's own interests and relative success and dominance over others (power, achievement); and (2) concerns for the welfare and interests of others (universalism, benevolence). The second-dimension contrasts "openness to change" and 
“conservation" value. This dimension captures the conflicts or synergies between: (1) values that emphasize the independence of thoughts, actions, feelings as well as readiness and willingness for change (self-direction, stimulation); and (2) values that emphasize protection and preservation of past and current conditions (security, conformity, tradition) (Schwartz 2012). To graphically portray these relationships, the theory arranges the ten values in a circular structure (Fig.3).

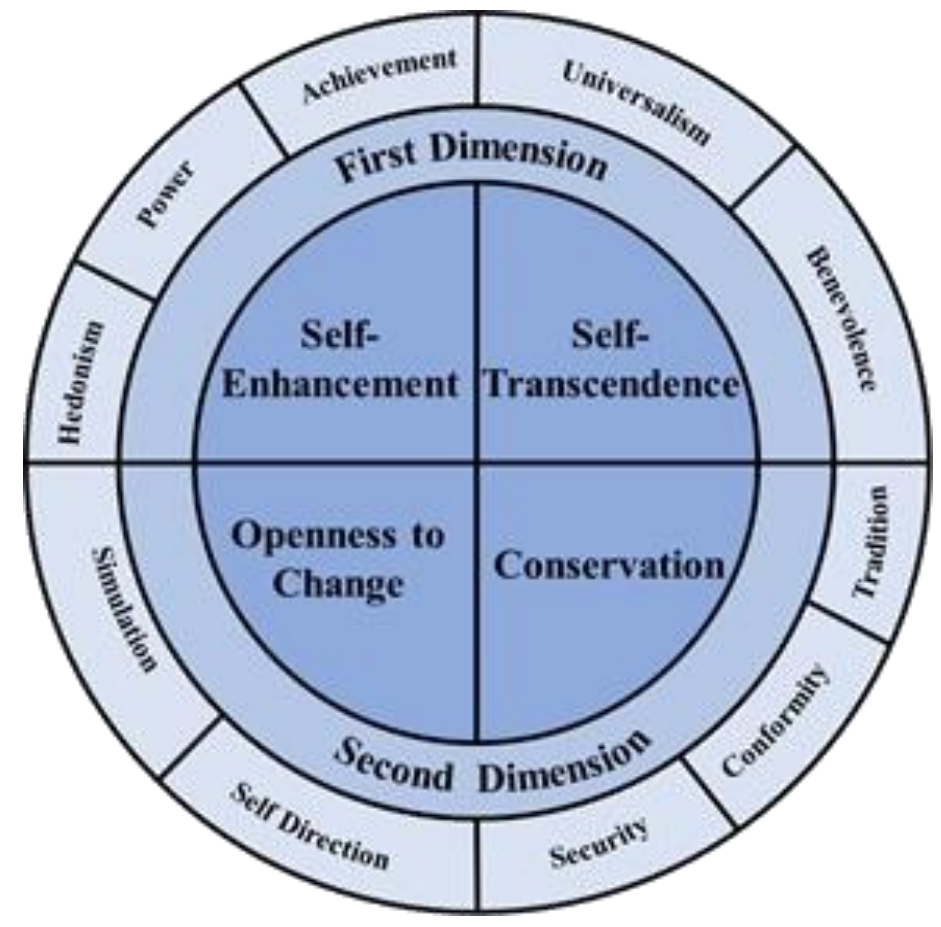

Figure 3: Schwartz's value framework (Schwartz 2012) 
Table 2: Schwartz's Ten Basic Human Values (Schwartz, 2012)

\begin{tabular}{|c|c|}
\hline & $\begin{array}{l}\text { Self-Direction refers to independent thoughts and actions, such as } \\
\text { choosing, creating, and exploring. } \\
\text { Examples of self-direction include creativity, freedom, self- } \\
\text { respect, self-growth, and privacy. }\end{array}$ \\
\hline & $\begin{array}{l}\text { Simulation refers to excitement, novelty, and challenges in life. } \\
\text { Examples of simulation include varied life circumstances, exciting } \\
\text { challenging tasks. }\end{array}$ \\
\hline & $\begin{array}{l}\text { Hedonism refers to pleasure and sensuous gratification for } \\
\text { satisfying oneself. } \\
\text { Examples of hedonism include pleasure, pursuing an enjoyable } \\
\text { life, and self-indulgent behavior. }\end{array}$ \\
\hline & $\begin{array}{l}\text { Achievement refers to personal success through demonstration of } \\
\text { competence according to social standards. } \\
\text { Examples of achievement include having a successful career, } \\
\text { playing an influential role, and receiving social recognition. }\end{array}$ \\
\hline & $\begin{array}{l}\text { Power refers to social status, prestige, and the ability to control } \\
\text { people and resources. } \\
\text { Examples of power include authority, wealth, social power, } \\
\text { preserving self-image, and social recognition. }\end{array}$ \\
\hline & $\begin{array}{l}\text { Security refers to safety, harmony, stability of relationships and } \\
\text { the self, and stability of society. } \\
\text { Examples of security include social order, family security, national } \\
\text { security, reciprocation of favors, and health. }\end{array}$ \\
\hline & $\begin{array}{l}\text { Conformity refers to restraint actions or impulses that could upset } \\
\text { or harm others or violate social expectations or norms. } \\
\text { Examples of conformity include self-reliance, obedience, self- } \\
\text { discipline, politeness, honoring parents and elders, loyalty, and } \\
\text { being responsible. }\end{array}$ \\
\hline & $\begin{array}{l}\text { Tradition refers to respect for, commitment to, and acceptance of } \\
\text { customs and ideas from one's culture and religion. } \\
\text { Examples of tradition include religion, beliefs, local culture, and } \\
\text { spiritual life. }\end{array}$ \\
\hline & $\begin{array}{l}\text { Benevolence refers to preserving and enhancing the welfare of } \\
\text { those with whom one is in frequent contact and related acts of } \\
\text { kindness. } \\
\text { Examples of benevolence include being helpful, honest, forgiving, } \\
\text { responsible, loyal, and cooperative, as well as a sense of belonging } \\
\text { and having socially supportive relations. }\end{array}$ \\
\hline & $\begin{array}{l}\text { Universalism refers to an understanding, appreciation, tolerance, } \\
\text { and protection of the welfare of people and nature. } \\
\text { Examples of universalism include social justice, equality, unity } \\
\text { with nature, wisdom, environmental protection, and inner } \\
\text { harmony. }\end{array}$ \\
\hline
\end{tabular}




\subsection{Collaborative Decision Making for Disaster Management}

Collaborative decision-making can be defined as combination and utilization of resources and management tools by several entities (stakeholders) to achieve a common goal (Kapucu and Garayev 2011). The decision is no longer associated with an individual. Collaborative decision-making is a type of participatory process in which multiple individuals acting collectively, analyze problems and emergency situations, consider and evaluate alternative course of actions, and then select the best from the solutions. It has been proved to be very beneficial in emergencies and disasters (Technologies for Sustainability Systems, 2014). In the context of disasters, collaborative decision making could involve a group of people, who are either experts or are impacted by disasters. Sharing information among the groups of people in collaborative decision leads to better decisions. Such decisions take into account a broader scope of information since each group member contribute unique information and expertise. Because of the diverse stakeholders that are involved, the collective knowledge on strategies or measures needed in an emergency situation can be significantly improved. It helps in building trusts and relationships among people. Through collaborative decision-making, jointly developed tools and procedures allow stakeholders to quickly adapt to changing environments. The benefits of collaborative decision-making can be summarized by the statement made by Henry Ford - "coming together is a beginning, staying together is progress and working together is success."

Research shows that the major challenge in emergency management or disasters is decision making under time pressure, with an overload of unconfirmed and uncertain information. This also includes conflicting information because of management of many 
people with distinct roles. Therefore, collaboration in these settings becomes crucial. In case of disaster management or other emergency situations, collaboration encompasses key elements such as coordination, communication formation for network, partnerships and interoperability (Kapucu et al. 2010). Research shows that collaborative decision is effective when information is offered or collected from heterogenous sources, which increases the trustworthiness and the reliability of the gathered information (Bannour et al. 2018). Collaborative decision making proves to be beneficial during disasters and crisis situations. It helps in building capacities, exchanging ideas, combining knowledge and information, and creating an effective strategies during a disaster or other emergency situations (Kapacu and Garayev 2011). Effective disaster management requires collective and cooperative emergency teamwork that involves various stakeholders, such as multilevel governments, private agencies, NGOs, and community residents (Subramaniam et al. 2010). The combination of collective efforts from these stakeholders proves to be an integral part in providing quick and effective response for disaster response and further in preparing mitigation plans to build more resilient communities (Zubir et al. 2016)

\subsection{State of the Art and Knowledge Gaps in Disaster Literature}

Based on a comprehensive literature review in the disaster domain (e.g., Adekola et al. 2020, Mojatahedi and Bee 2017; Räikkönen et al. 2017, Emmanuel 2013, Lindell et al. 2007), three main knowledge gaps were identified. First, there is lack of research that explicitly and systematically understands stakeholder values in the context of disasters. Human values and individual systems of value priorities are the key predictive and explanatory factors in investigating decision making (Cheng and Fleischmann 2010); and, they motivate and guide actions and decisions (Schwartz 2012). To deliver greater 
collective value to all the stakeholders, there is a need to explore how to better prepare for, respond to, recover from, and mitigate the impacts of disasters to fulfill stakeholder values and how the decisions can be made to align with stakeholder value priorities.

Although stakeholder values and their link to decision making may appear welladdressed in the literature (e.g., Hostmann et al. 2005; Keeney 1992; Lynam et al. 2007; Tantalo and Priem 2016), it is one of the least studied and understood areas. For example, researchers have emphasized the importance of engaging stakeholders in decision making on disaster management (e.g., Kapucu and Garayev 2011), and proposed approaches for better involving stakeholders in disaster management (e.g., Ganapati and Ganapati 2009; Kapucu and Garayev 2011; Ganapati and Mukherji 2014; Kapucu and Van Wart 2006). While the underlying goal of stakeholder engagement is to account for their diverse values in decision making, these efforts have not explicitly and systematically captured the stakeholder value systems, however.

Second, there is a lack of research that compares the differences among different stakeholder sectors' value systems in the context of disasters. The differences in stakeholders' value systems could become a central cause of conflicts and disputes (Jehn 1994) while trying to prepare for, responds to, and recover from disasters. For example, tenants may focus on their safety and building robustness in a hurricane, while building owners may see their properties as a short-term investment and prefer to buy insurance with lower cost instead of retrofitting the building with high impact windows. Stakeholders constantly negotiate, compete and/or cooperate with one another; and their values are fundamentally important in their decisions in the context of disasters. Existing research (e.g., Choi and Brower 2006; Choi and Kim 2007; Guo and Kapucu 2015; Hu et al. 2014; 
Kapucu and Garayev 2011; Kapucu and Garayev 2014) emphasizes the importance of multi-sector stakeholder collaboration in facilitating more effective decision making for disaster management. Much of this literature hails from the public administration discipline. Such orientation is not surprising given this discipline's focus on public sector agencies and the "hollowing" out of the state, which involves contracting with non-profit and private sector entities to provide public services (Frederickson and Frederickson 2006; Milward and Provan 2000; Rhodes 1994). Although this literature advocates for different approaches and tools for studying multi-stakeholder collaboration, it fails to comparatively analyze how stakeholder values vary due to stakeholders' specific roles and responsibilities.

Third, there is lack of research that analyzes how stakeholder value systems are dynamically affected by natural disasters. Stakeholder value systems are dynamic and uncertain (Daniel et al. 2013; Rudnev 2014). Value priorities have been found to change when individuals go through major life events such as wars and migration (Bardi et al. 2014; Daniel et al. 2013; Rudnev 2014). With time elapsing after a life transition of a disastrous event, rebound effects come into play (i.e., values may return close to their baseline levels) (Lönnqvist et al. 2013; Verkasalo 2006). During a disaster event, stakeholders may have an entirely different set of value priorities, comparing with their value priorities in non-disaster time. Existing research has mainly focused on examining socioeconomic or demographic variables (e.g., gender, poverty, unemployment) as antecedents of individuals' value priorities (Hitlin and Piliavin 2004; Schwartz 2004). Research shows that people's age, education, gender, and other characteristics could significantly determine the life circumstances to which they are exposed to, and thus will 
affect their value priorities (Schwartz 2004). For example, older people may attach higher importance to security values because a safe and predictable environment becomes more critical as older people's capacities to cope with change wanes. In terms of gender difference, women show more concern for an ethic of care and responsibility, while men attach higher priorities to ethic of rights based on justice and fairness (Schwartz 2004). These important literatures have provided valuable understanding of human values and how different demographic and socioeconomic variables could affect people's value priorities. However, contextual variables (e.g., disastrous context) may be just as important to consider to understand value priorities and their potential changes over time more thoroughly. There is little research that has been conducted to understand how human values are dynamically affected by natural disasters. 


\section{RESEARCH OBJECTIVES AND QUESTIONS}

To address the above-mentioned knowledge gaps, this study aims to understand and analyze the dynamics of multi-sector stakeholder value systems during the preparedness, response, recovery, and mitigation phases of Hurricane Michael. It aims to address the following research questions:

i. What do public stakeholders, private stakeholders, NGOs, and community residents value in the context of Hurricane Michael?

ii. What are the value priorities of the multi-sector stakeholders?

iii. Are there any similarities or differences of stakeholder value priorities across different sectors?

iv. How do stakeholder value priorities change throughout different phases of Hurricane Michael (i.e., preparedness, response, recovery, and mitigation phases)? 


\section{RESEARCH METHODOLOGY AND CONTEXT}

A qualitative research approach was adapted to identify multi-sector stakeholder values in the context of Hurricane Michael. Hurricane Michael was a Category 5 storm with maximum sustained wind speeds reaching $161 \mathrm{mph}$. It made landfall in Florida's Northwest Panhandle region on October 10, 2018. It was the strongest storm that hit the contiguous U.S. in more than 25 years, and the most powerful on record in the Florida Panhandle area (Reeves and Lush 2018). According to a NOAA report (NOAA 2018), approximately 75 deaths were caused directly or indirectly by Hurricane Michael. Along with tragic losses of lives, the catastrophic wind damage and devastating flooding have caused around $\$ 53$ billion losses to the U.S. economy (Perryman 2018).

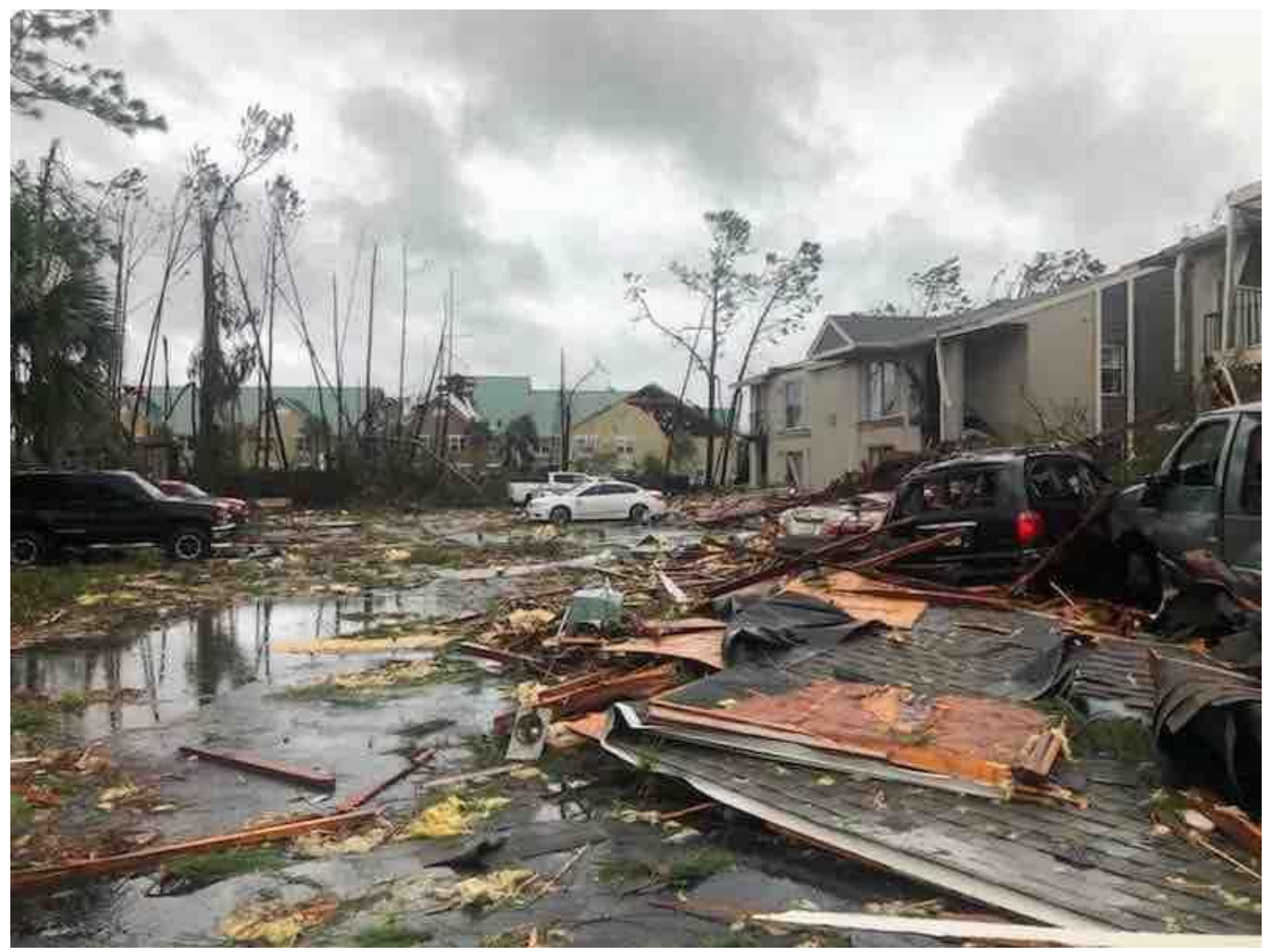

Figure 4: Housing destructions caused by Hurricane Michael in Panama City 
Thousands of people living in the hurricane path were evacuated after the hurricane. Cities and towns, such as Mexico Beach, Panama City, Panama City Beach, Marianna, were still full of devastation when this study was conducted. In addition to the lifethreatening storm surge, structural damage was extensive, particularly across the Florida Panhandle area. Preliminary data assessments indicate almost 50,000 structures were affected, and more than 3,000 structures were destroyed (National Weather service 2018). Figure 4 shows the housing destructions caused by Hurricane Michael in Panama City.

The wind damage was not confined to the coastline but extended well inland. In Marianna, businesses lost their roofs and the exterior wall of some buildings collapsed as the roof was lost. In addition to extensive structural damage, hurricane force winds caused widespread power outages across a large portion of the tri-state region. Nearly $100 \%$ of customers across a large portion of the Florida Panhandle lost power, with some of these outages lasting weeks. The catastrophic winds also resulted in damage to the timber and agricultural communities across Florida and Georgia. According to the Florida Forest Service, in Florida, timber damage costs estimates were over $\$ 1.2$ billion dollars with almost 3 million acres of forested land damaged. (National Weather service, 2018). Figure 5 shows a track map of Hurricane Michael (map resources NA; National Weather Service 2018). 


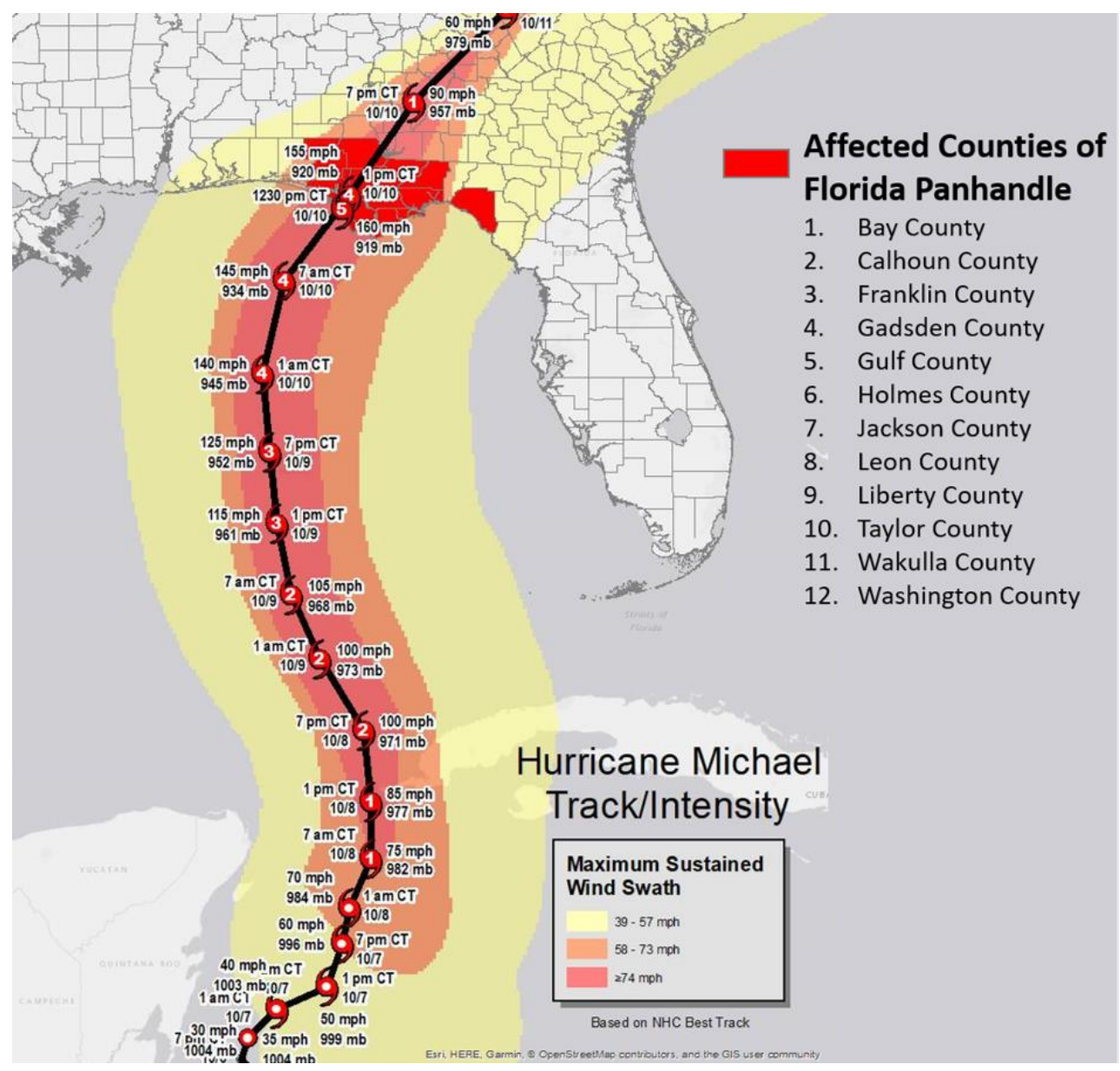

Figure 5 : Track map of Hurricane Michael \& the counties affected (FEMA 2018)

The qualitative method was used because qualitative data offers detailed descriptions of research subjects' feelings, opinions, and experiences, and the interpretation of values are deeply embedded in the feelings, opinions, and experiences of stakeholders. The open-ended structures of qualitative research also allow for a deep analysis of reasons and rationales underneath the responses and the extraction of new information and knowledge from research participants (Singer and Couper 2017). Since human values and value priorities are intangible and are deeply embedded in the people's consciousness, qualitative method is the most appropriate way to discover and identify the values. 
The primary data collection method in the study was in-depth semi-structured interviews with community stakeholders who were impacted by Hurricane Michael in the Florida Panhandle area. The following sections discuss about the interview design, data collection and preparation, and data analysis methods.

\subsection{Interview Design}

The interviews followed a semi-structured format. In the interview instrument, a set of open-ended questions were grouped into five major sections based on disaster management cycles: (1) before Hurricane Michael (normal condition); (2) preparedness; (3) response; (4) recovery; and (5) future of the community (mitigation). Under each of these sections, a similar set of open-ended questions were asked.

Examples to the questions include:

(1) What did you/your group/your organization value about this community the most before Hurricane Michael?

(2) Can you please tell me why this mattered to you/your group/your organization the most at that time?

(3) Given that this is what you valued at the time, please tell me one thing that you should have done but did not do right before Hurricane Michael? and

(4) Please explain why you think doing this would have helped the community at the time. At the end of the interview, the background information of the interviewees was solicited, including age, gender, education, ethnicity, race, profession, and work experience. 


\subsection{Sample and Data Collection}

The interviews were conducted with 51 individuals $(\mathrm{n}=51)$ face to face or over the phone through 41 interviews distributed across Bay, Leon and Gulf Counties in Florida. The face-to-face interviews were conducted during three visits to the Florida Panhandle area from December 2018 to February 2019, followed by phone interviews from March 2019 to May 2019. Among the 41 interviews, 37 of them were individual interviews and 4 of them were group interviews. The following stakeholders were targeted for the interviews: (1) representatives from public sector agencies (e.g., state emergency management departments, city governments), such as city commissioners, city managers, city planners, emergency management officers, department of transportation officers, and chairpersons of the counties; (2) representatives from private sector entities (e.g., construction firms, touristic businesses, healthcare facilities, and financial institutions), such as small business owners, doctors, construction project managers, civil engineers, bankers, insurance agents, school principals; (3) representatives from the NGOs (e.g., volunteer organizations and groups) such as church authorities; and, (4) residents of impacted areas.

The initial set of interviewees were identified through a review of secondary sources (e.g., websites of government agencies, local news websites and articles). These interviewees were either individuals who have had disaster management responsibilities or liabilities (e.g., emergency managers, housing contractors) or were directly or indirectly affected by Hurricane Michael (e.g., local business owners). A snowball sampling technique, a nonprobability sampling technique where exiting interviewees recruit future interviewees from among their acquaintances (Goodman 1961), was then used to expand 
the initial list of interviewees. The descriptive statistics of study participants are summarized in Table 3.

Table 3: Demographic Information of the Interviewees

\begin{tabular}{|c|c|c|c|c|c|}
\hline & $\begin{array}{c}\text { Public } \\
\text { Stakeholder }\end{array}$ & $\begin{array}{c}\text { Private } \\
\text { Stakeholder }\end{array}$ & NGO & $\begin{array}{l}\text { Community } \\
\text { Resident }\end{array}$ & $\begin{array}{c}\text { All } \\
\text { Stakeholder }\end{array}$ \\
\hline \multicolumn{6}{|c|}{ Stakeholder group } \\
\hline No of Stakeholders & 12 & 18 & 9 & 12 & 51 \\
\hline \multicolumn{6}{|c|}{ Region } \\
\hline Bay County & 9 & 16 & 3 & 10 & 38 \\
\hline Gulf County & 3 & 2 & 0 & 1 & 6 \\
\hline Leon County & 0 & 0 & 1 & 1 & 2 \\
\hline Others & 0 & 0 & 5 & 0 & 5 \\
\hline \multicolumn{6}{|c|}{ Gender } \\
\hline Male & 10 & 16 & 4 & 9 & 39 \\
\hline Female & 2 & 2 & 5 & 3 & 12 \\
\hline \multicolumn{6}{|c|}{ Age } \\
\hline $18-25$ & 1 & 1 & 0 & 2 & 4 \\
\hline $26-30$ & 2 & 0 & 0 & 0 & 2 \\
\hline $31-35$ & 2 & 5 & 2 & 1 & 10 \\
\hline $36-40$ & 1 & 3 & 2 & 4 & 10 \\
\hline $41-45$ & 1 & 3 & 2 & 0 & 6 \\
\hline $46-50$ & 3 & 2 & 1 & 1 & 7 \\
\hline $51-55$ & 1 & 3 & 2 & 3 & 9 \\
\hline $56-60$ & 0 & 1 & 0 & 0 & 1 \\
\hline $61-65$ & 1 & 0 & 0 & 1 & 2 \\
\hline \multicolumn{6}{|c|}{ Education } \\
\hline High school degree & 0 & 0 & 0 & 0 & 0 \\
\hline Bachelor's degree & 6 & 9 & 5 & 4 & 24 \\
\hline Graduate degree & 3 & 4 & 3 & 4 & 14 \\
\hline Associate degree & 0 & 1 & 0 & 2 & 3 \\
\hline Professional degree & 1 & 2 & 1 & 0 & 4 \\
\hline Others (Credit, No college) & 2 & 2 & 0 & 2 & 6 \\
\hline \multicolumn{6}{|c|}{ Work Experience in current company (years) } \\
\hline Less than 1 year & 0 & 2 & 0 & 3 & 5 \\
\hline More than 1 but less than 3 & 1 & 0 & 0 & 1 & 2 \\
\hline More than 3 but less than 6 & 2 & 4 & 1 & 2 & 9 \\
\hline More than 6 but less than 9 & 2 & 1 & 3 & 2 & 8 \\
\hline More than 9 but less than 12 & 3 & 3 & 3 & 0 & 9 \\
\hline 12 years and more & 4 & 8 & 2 & 4 & 18 \\
\hline \multicolumn{6}{|c|}{ Race } \\
\hline Asian & 1 & 7 & 0 & 8 & 16 \\
\hline White & 9 & 9 & 9 & 4 & 31 \\
\hline Black or African American & 2 & 1 & 0 & 0 & 3 \\
\hline $\begin{array}{l}\text { American Indian or Alaska } \\
\text { Native }\end{array}$ & 0 & 1 & 0 & 0 & 1 \\
\hline
\end{tabular}


All the interviews took place during the daytime as per the availability of the stakeholders and were recorded upon receiving the approval of study participants. Out of the 51 interviewees, 4 interviewees did not allow for recording of the interviews. For these cases, detailed notes were taken. The interviews were in a semi-structured format, which allowed for a comprehensive, in-depth discussion with the interviewees and for the researchers to modify the questions as per the profession and/or background of the interviewees and to identify new ideas or additional insight relevant to the discussion. For example, during the interviews with the government officials, additional questions were added to include topics such as what their scope of work was during the disaster, what their expectations from the residents are, and what they value about the civil infrastructure.

Prior to coding of data, recorded interviews were automatically transcribed using Sonix (SONIX 2019) and were checked for accuracy and revised manually. For the four interviews in which recording was not permitted by the interviewees, detailed notes were taken. Data collected from the interviews (including the transcription data and notes) was imported into NVivo, a qualitative analysis software. The interview data was supplemented with secondary data, including reports and articles published by FEMA, government agencies, international organizations, academic researchers, NGOs, and media (e.g., Chang et al. 2010; Chhotray and Few 2012). 


\subsection{Data Analysis}

In this study, a hybrid approach was used to derive the values of multi-sector stakeholders. The hybrid approach employs a combination of both the top-down and the bottom-up analysis (Zhang and El-Gohary 2015). The top-down approach starts by identifying and defining the most abstract values and extends to more specific values, whereas a bottom-up approach starts by identifying and defining the most specific values and classifies them into abstract ones (Zhang and El-Gohary 2015). Benchmarking Schwartz's Theory of Basic Human Values (Schwartz 2012), the four categories from two bipolar dimensions, including conservation, openness to change, self-transcendence and self-enhancement, were used to construct a value framework. Based on these higher-level values, the interview data was analyzed to derive the sub-level values. For example, under the "conservation" value, four specific values were identified from the interview data, including "safety", "resource efficiency", "environmental preservation", “cultural preservation and infrastructure restoration." These high-level values and specific values were coded as parent nodes and child nodes in NVivo, respectively. All the interview data were then coded based on these nodes. To further classify the interview data based on stakeholder groups and disaster phases, two additional sets of nodes were created, including (1) nodes for different types of stakeholders (i.e., public, private and non-profit sector stakeholders, and community residents); and, (2) the nodes for different phases of a disaster (i.e., preparedness, response, recovery and mitigation). This polymorphic way of coding and analysis supported the identification of values and analysis of value priorities for (1) different types of stakeholders and/or (2) at different phases of Hurricane Michael. 


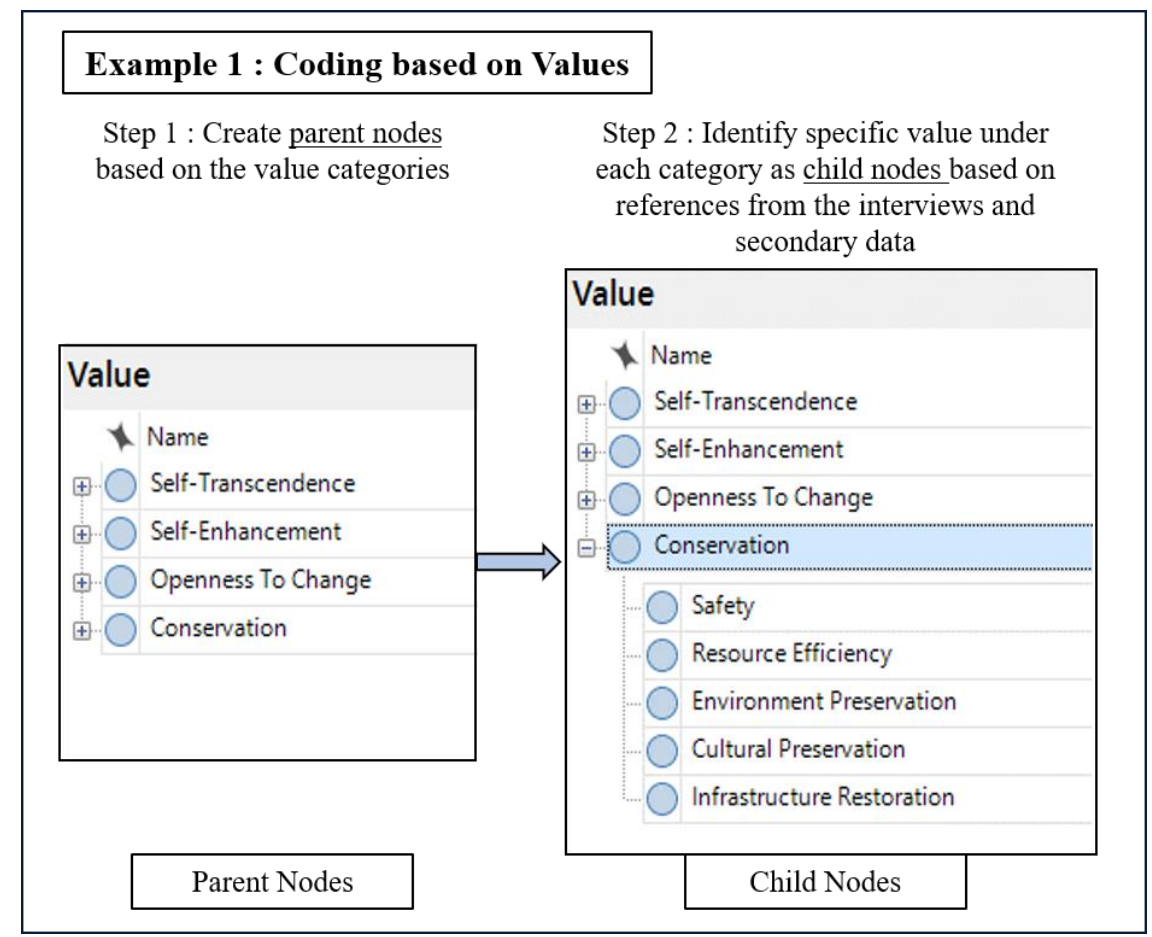

Figure 6: The coding of interview data based on Value using NVivo

Example 2 : Coding based on Phases of disaster

Step 1 : Create parent nodes based on the Phases of disaster

\section{Phases of Disaster}

1 Name

†. Prior to Hurricane

†. Preparedness

†. Response

$\doteqdot \bigcirc$ Recovery

†. Mitigation

Parent Nodes
Step 2 : Identify value categories under every phase of disaster as child nodes based on references from the interviews and secondary data

\begin{tabular}{|l|} 
Phases of Disaster \\
Pame \\
Prior to Hurricane \\
Separedness \\
Self Transcendence \\
Conservation \\
Response \\
\hline Recovery \\
Mitigation \\
\hline Child Nodes \\
\hline
\end{tabular}

Figure 7: The coding of interview data based on Disaster phases using NVivo 


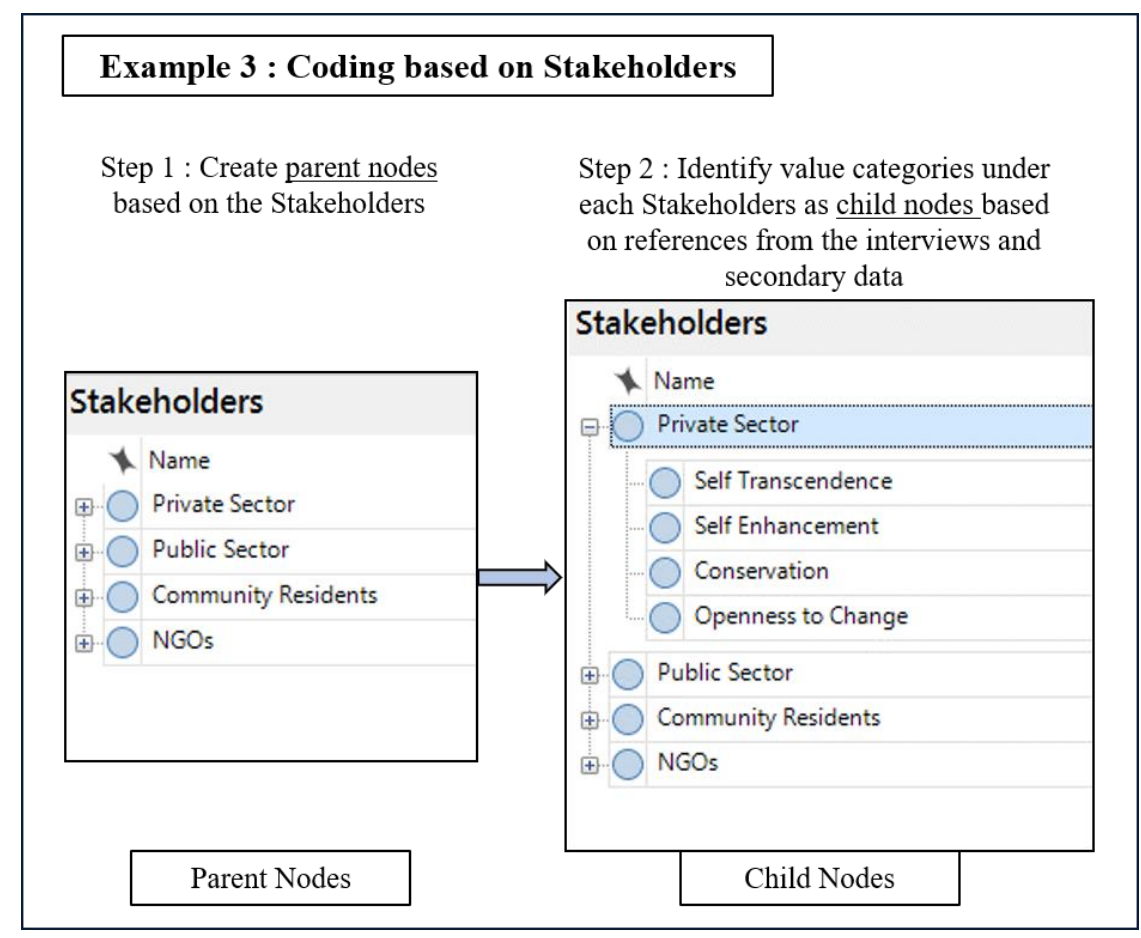

Figure 8: The coding of interview data based on Stakeholders using NVivo 


\section{RESEARCH FINDINGS}

Below are the study's findings on identified stakeholder values with detailed explanations on top five values, followed by stakeholder value priorities across sectors and across disaster phases.

\subsection{Identification of Stakeholder Values}

A total of 16 values were identified from the coded data and were first classified based on Schwartz's Theory of Basic Human Values (Fig. 3). The four main categories are conservation, openness to change, self-transcendence, and self-enhancement (Fig. 9):

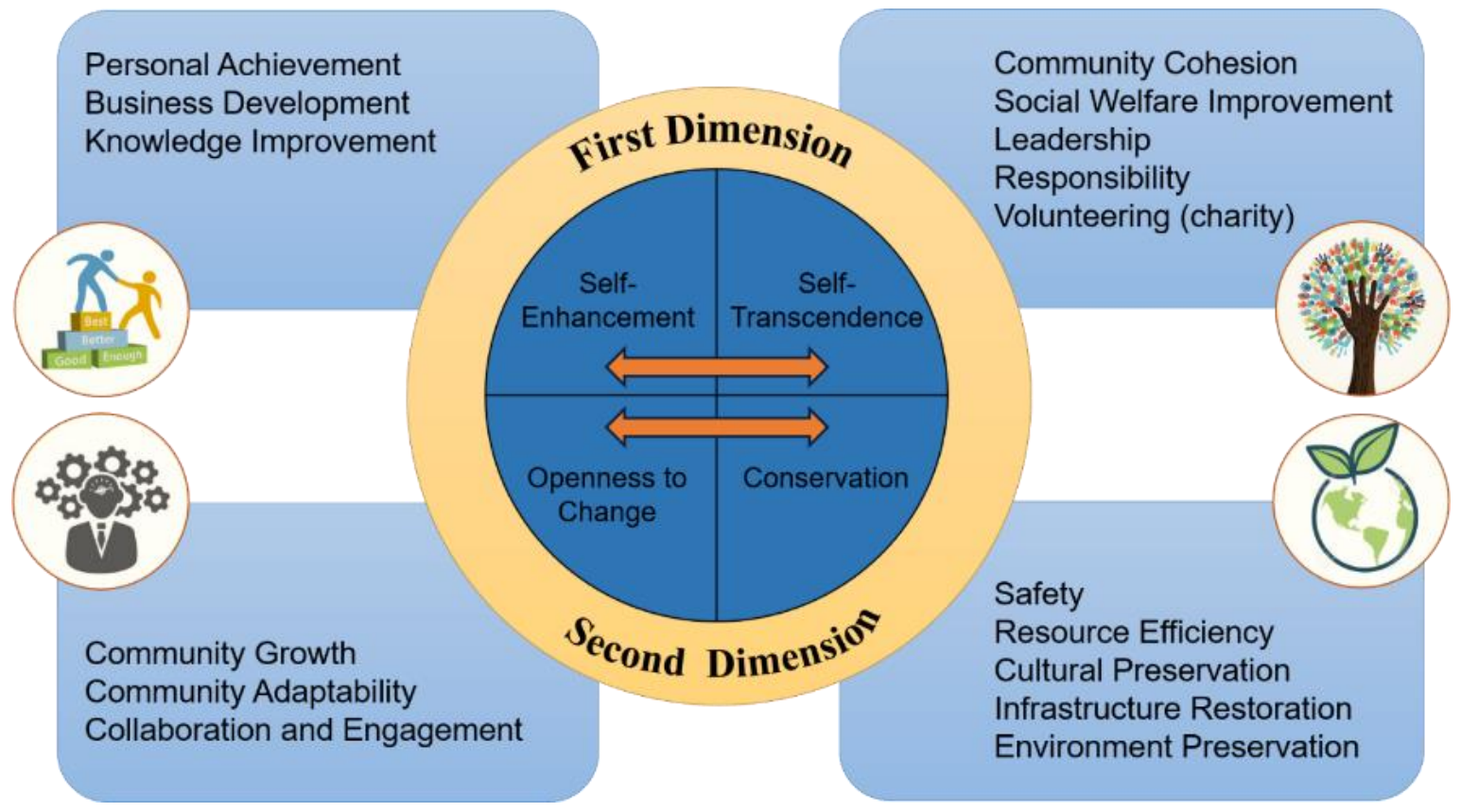

Figure 9: Identified stakeholder values in the context of Hurricane Michael

1) Conservation

In the context of Hurricane Michael, the conservation value includes safety, resource efficiency, environmental preservation, cultural preservation and infrastructure restoration.

- Safety refers to the value that is concerned with the conditions of being protected 
from disasters. Safety has multiple levels and dimensions, including personal life safety, family safety, employee safety, home safety, business property safety, and public safety.

- Resource efficiency refers to the value that is concerned with using or consuming resources (e.g., water, energy, gas, materials, staffing) more efficiently throughout different phases of disasters.

- Environmental preservation refers to the value that is concerned with the protection, preservation, restoration, and/or enhancement of ecosystems (e.g., wetlands, coral reefs, forests), biological resources (e.g., wildlife), geological formations, and hydrology.

- Cultural preservation refers to the value that is concerned with the protection or preservation of the local historical or cultural resources (e.g., historical sites) from disasters.

- Infrastructure restoration refers to the value that is concerned with restoration and redevelopment of disrupted and damaged structures and facilities (e.g., health facilities, roads, bridges, shopping centers, community development zones, religious structures).

\section{2) Openness to Change}

In the context of Hurricane Michael, "openness to change" refers to community growth, community adaptability, collaboration and engagement.

- Community growth refers to the value that is concerned with opportunities of growth brought by disasters. 
- Community adaptability refers to the value that is concerned with the ability of community members to adjust their responses to the changing environment and/or conditions caused by disasters.

- Collaboration and engagement refers to the value that is concerned with actions of working together among multi-sector stakeholders to cope with damage and stresses caused by disasters.

\section{3) Self-transcendence}

In the context of Hurricane Michael, self-transcendence includes community cohesion, social welfare improvement, leadership, responsibility and altruism.

- Community cohesion refers to the value that is concerned with togetherness and bonding exhibited by members of a community prior to, during and following a disaster event. It includes features such as a sense of belonging, trust in neighbors, and/or assistance and support from neighbors.

- Social welfare improvement refers to the value that is concerned with providing public or private social services for assisting disadvantaged groups (e.g., the elderly, disabled, economic disadvantaged) during disasters.

- Leadership refers to the value that is concerned with the actions of leading the community to prepare for, respond to, and recover from disasters. It requires skills such as decisiveness, integrity, relationship building, problem-solving, and communication.

- Responsibility refers to the value that is concerned with the sense of having a duty to or having control over the efforts for disaster preparedness, response, recovery and mitigation. 
- Altruism refers to the value that is concerned with altruistic activities or attitudes that an individual or a group of people provide services willingly for no financial gain (e.g., volunteering activities) in the context of a disaster.

4) Self-enhancement

In the context of Hurricane Michael, self-enhancement includes personal achievement, business development, and knowledge improvement.

- Personal achievement refers to the value that is concerned with personal success through demonstrating competencies according to social norms.

- Business development refers to the value that is concerned with building new opportunities in business and growth in the future.

- Knowledge improvement refers to the value that is concerned with acquiring new knowledge about disaster management through organizational skills, communications, education and training, and government support.

\subsection{Stakeholder Value Priorities}

The identified values were ranked based on the percentage of interviewees who mentioned the values during the interviews. Fig. 10 shows the overall rankings of values for all stakeholders across different phases of Hurricane Michael. Detailed discussions on the top five most important values are presented in the following paragraphs: safety, resource efficiency, community adaptability, community cohesion and community growth. 


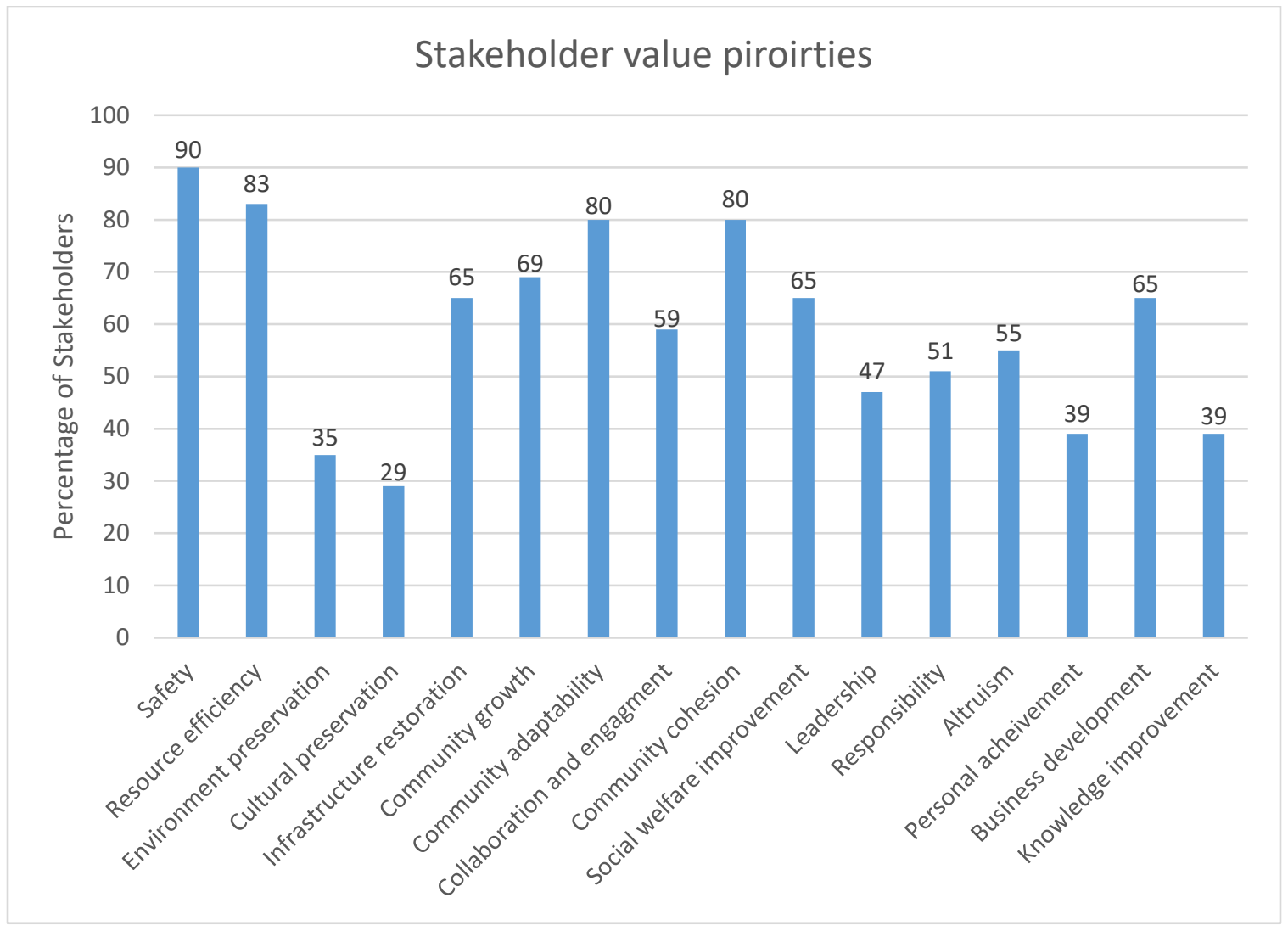

Figure 10: Stakeholder value priorities

\subsubsection{Safety}

Among the 16 values, safety was mentioned or discussed by $90 \%$ of the interviewees, thus it was considered as the most prioritized value based on the stakeholders' perspectives. As safety includes different dimensions, different stakeholders have varying value priorities towards different safety dimensions. For example, the interviewees from the private sector and community residents focus more on personal life safety, family safety, employee safety, and safety of personal belongings. As mentioned by one of the interviewees from the tourism sector, when Hurricane Michael was initially predicted to be a Category 2 hurricane, the local residents' initial value priority was the potential economic effects of Hurricane Michael because $30 \%$ of their jobs are tied to 
tourism. However, as the hurricane approached, "our main value had nothing to do with tourism business," one interviewee said, and added: "our main value was the safety of our family and friends." On the other hand, public stakeholders and NGOs attached high importance to the safety of the whole community besides their personal life and property safety. They took different actions to ensure the safety of the entire community. For example, an interviewee from a disaster relief and recovery focused non-governmental organization claimed that their primary value was to "serve and ensure the safety of the people who are affected in the disaster." Similarly, a government employee involved in emergency management mentioned that the number one goal of emergency management is to "ensure the safety of the whole community." To do that, he emphasized, that all different sectors need to work collaboratively to ensure that the communities are aware of the emergency knowledge and of resources available to them in the disaster. In addition, he highlighted the importance of mitigation efforts. For example, more stakeholders and sectors need to be engaged in emergency training and exercises throughout the state. "We should not wait until the disaster hits us, we need to take better mitigation actions and be better prepared," the interviewee said. Another interviewee from the public sector mentioned that a public safety risk management framework or flow chart could/should be designed to include multiple sectors with clear definitions on the roles and responsibilities to collaboratively reduce disaster risks.

\subsubsection{Resource Efficiency}

Resource efficiency was the second most emphasized value according to the responses of the interviewees. Disaster management involves a coordinated and cooperative process of preparation to match the urgent needs of the public with limited 
resources. One of its critical goals is to ensure an efficient use of lifesaving and recovery resources, including water, power, gas, food, materials, and staffing. According to an interviewee from the public sector involved in transportation, one of the most challenging tasks during the disaster response phase was the coordination of limited resources to effectively remove the debris and open up the roads. "After Hurricane Michael, all roads are impacted, all roads need to be reopened, but we only have limited resources," the interviewee said, "How to make a better use of these limited resources became a challenge." Similarly, limited access to water, food, power, gas, and medical supplies were mentioned by several interviewees from the private sector. "To ensure the patients get the medicine they need after the disaster, I prepared all the prescriptions before Michael hit us," said one interviewee who works in a private health clinic, "because I knew there would be limited medical supplies once Michael passes." The local infrastructure conditions further worsened the limited resource supplies as many local roads were completely inaccessible due to debris and fallen trees and branches. In some regions, water and power outages lasted for several weeks after the disaster because of the severely damaged infrastructure. Efficiently using and allocating limited resources became an important value priority to the stakeholders in that particular context.

\subsubsection{Community Adaptability}

Community adaptability is also among the highest ranked values with $80 \%$ of interviewees mentioning the importance of it. Community adaptability is a critical element of community resilience as "community resilience is composed of a set of networked adaptive capacities" (Plough et al. 2013, p. 1191). The adaptability of the communities in the Florida Panhandle was tested and challenged by the rapid intensification of Hurricane 
Michael. Hurricane Michael rapidly intensified from a tropical storm into a Category 5 hurricane in three days, leaving little time for preparedness. Many residents decided to shelter in place as they did not have time to safely evacuate. One of the interviewees mentioned that the news of the hurricane was not taken seriously until the storm had actually started. As a result, local residents were not prepared for the disaster to be of this magnitude and they did not store enough resources to withstand the resulting damage.

Meteorologists have provided a number of explanations for the rapid intensification of hurricanes and storms in recent years, one of which being climate change and global warming. The climate-added rapid intensification will make hurricanes increasingly difficult to predict in the future (Pielke et al. 2005; Mousavi et al. 2011). Given such situation, one emergency management officer emphasized that "to build the capacity of community adaptability, we should not just focus on the disaster response phase. Rather, we need to spend more efforts on disaster mitigation". "Public education and outreach are the key; training and exercises are the key," he highlighted. Emergency management officials highlighted that such education, training, and exercises should engage all different sectors, including different levels of government, private sectors, NGOs, and the community residents. To build more resilient communities, different stakeholders should not only collaboratively adjust to short-term extreme events such as Hurricane Michael, but also adjust to the gradually changing climatic conditions to prepare for and deal with the effects of climate change in the long-term, especially coastal flooding, erosion, and ecosystem changes.

\subsubsection{Community Cohesion}

Similar to community adaptability, community cohesion and trust in neighbors 
were prioritized by the stakeholders. This result coincides with a number of research studies (e.g., Chang 2010; LaLone 2012; Tompson et al. 2013, Townshend et al. 2015) that confirm social cohesion as a critical component in building more resilient communities as well as earlier studies that have documented cohesive post-disaster behavior (e.g., Bardo 1978; Barton 1969; Drabek and McEntire 2003; Fritz and Mathewson 1957; Ganapati 2009; Parr 1970). For example, Tompson et al. (2013) proved that communities with a strong sense of social connection recovered at a faster pace. People living in those communities with the fastest recovery were more inclined to say that "others can be trusted" and "the disaster brought out the best in their neighbors." In communities that had a harder time bouncing back, more people reported seeing looting, vandalism, and hoarding of food and water (Tompson et al. 2013).

During Hurricane Michael, stakeholders emphasized the importance of community cohesion and took actions to help or support one another. Hurricane Michael caused catastrophic impact to every individual, household, and community in the area. Many residents' houses were damaged or destroyed, and they suffered from water, power, and phone service outages due to damages to critical infrastructure systems (e.g., transportation, electricity, water, sewer). In the immediate aftermath of Hurricane Michael, although federal and state governments quickly announced that emergency aid had been made available to the affected communities, some of the hardest-hit areas were nearly impossible to reach because the roads were flooded or buried with debris. As a result, community residents and private stakeholders volunteered to check to ensure the safety of their neighbors after the disaster, shared resources such as water, food, gas, and generators, and helped each other conduct the initial damage assessment and rebuild. For example, in 
Tallahassee, some grocery stores were open the day after the hurricane, and the store employees started to work from 3 a.m. to ensure that food and other supplies were available for customers. A physician, who lost the home herself, mentioned that she tried to help her patients "at any cost." She had filled all the prescriptions during the preparedness phase because she expected people would need their medicines during and immediately after the disaster. She reopened her clinic the day after the disaster to serve the patients when the two large hospitals in the area were severely damaged. Public sector agencies also took all the necessary actions to reach out to and improve the conditions of the impacted communities and they worked extra hours for the betterment of communities. For example, a government official mentioned that his priority immediately after the disaster was not to repair his own damaged house, but rather "to make sure all citizens were accessible to the drinking water and medical facilities."

\subsubsection{Community Growth}

Around $69 \%$ of interviewees discussed about the importance of community growth. Stakeholders affected by Hurricane Michael expressed a surprisingly positive and optimistic attitude towards Hurricane Michael's impacts. Although their homes, businesses, and infrastructure systems were severely damaged, they emphasized that "it opens doors for growth and change." When talking about the future of their communities, they are determined to rebuild stronger structures instead of restoring what was there prior to the disaster. For example, a public sector employee emphasized that the building codes should and will be upgraded due to the impact of Hurricane Michael, and he said, "there is no doubt that [the standard in the building code] should be raised." Most new homes and commercial buildings in Miami-Dade County must be built to withstand the design wind 
speed of approximately $175 \mathrm{mph}$, but these specifications are only approximately $120 \mathrm{mph}$ in the Mexico Beach area. To build more resilient communities in the Florida Panhandle area, there is a growing consensus that building codes along the Florida Panhandle area should be stricter.

Similarly, a number of interviewees from the private sector and community residents, who have lived in the Florida Panhandle for their entire lives, are optimistic about the future of their communities; they embrace changes and are looking forward to more resilient communities. "Panama City has not changed for decades, now it is the time for a more resilient community," said a business owner who has lived in Panama City for more than 30 years. "Panama City Beach is a small town that was developing slowly at its pace. After the hurricane, there will be more motivations among people to rebuild and grow," another property developer from Panama City Beach stated, "the city is generally very resilient, and it will always come back strong. Now the goal is to grow back and grow stronger." Similarly, an interviewee who is the owner of a construction company at Panama City mentioned that "it's going to be a better future as the development in Florida Panhandle has always been laid-back, but this time it's an opportunity to rebuild and grow with new codes and regulations."

\subsection{Stakeholder Value Priorities Across Sectors: Similarities and Differences}

Stakeholder value priorities were further analyzed based on the stakeholder sectors the interviewees belong to, and the results of stakeholder value priorities based on stakeholder sectors are presented in Fig. 11 and Table 4. As per Fig. 11 and Table 4, although these is a general consensus on the importance of the identified values, the ranks of these values were different based on different stakeholders' perspectives. This indicates 
that stakeholders from different sectors have different value priorities, and the importance of some specific values were emphasized by only certain groups of stakeholders. These differences may be attributed to various factors such as differences in (1) personal or work responsibilities, (2) concerns and needs, (3) interests or preferences, (4) knowledge backgrounds, (5) previous disaster experiences, and (6) professional backgrounds.

Table 4: Stakeholder Value Priorities

\begin{tabular}{|c|c|c|c|c|c|c|c|c|c|c|}
\hline \multirow[t]{2}{*}{ Values } & \multicolumn{2}{|c|}{$\begin{array}{l}\text { Public } \\
\text { Stakeholders } \\
\text { (S1) }\end{array}$} & \multicolumn{2}{|c|}{$\begin{array}{l}\text { Private } \\
\text { Stakeholders } \\
(\mathrm{S} 2)\end{array}$} & \multicolumn{2}{|c|}{$\begin{array}{l}\text { NGOs } \\
\text { (S3) }\end{array}$} & \multicolumn{2}{|c|}{$\begin{array}{l}\text { Community } \\
\text { Residents } \\
\text { (S4) }\end{array}$} & \multicolumn{2}{|c|}{$\begin{array}{l}\text { All } \\
\text { Stakeholders } \\
(\mathrm{S})\end{array}$} \\
\hline & $\%$ & Rank & $\%$ & Rank & $\%$ & Rank & $\%$ & Rank & $\%$ & Rank \\
\hline Safety & 75 & 2 & 89 & 1 & 100 & 1 & 100 & 1 & 90 & 1 \\
\hline $\begin{array}{l}\text { Resource } \\
\text { efficiency }\end{array}$ & 75 & 2 & 78 & 3 & 100 & 1 & 83 & 2 & 83 & 2 \\
\hline $\begin{array}{l}\text { Environmental } \\
\text { preservation }\end{array}$ & 67 & 8 & 6 & 16 & 67 & 7 & 25 & 15 & 35 & 15 \\
\hline $\begin{array}{l}\text { Cultural } \\
\text { preservation }\end{array}$ & 50 & 12 & 11 & 15 & 22 & 13 & 42 & 12 & 29 & 16 \\
\hline $\begin{array}{l}\text { Infrastructure } \\
\text { restoration }\end{array}$ & 75 & 2 & 61 & 8 & 56 & 9 & 67 & 7 & 65 & 6 \\
\hline $\begin{array}{l}\text { Community } \\
\text { growth }\end{array}$ & 75 & 2 & 72 & 7 & 56 & 9 & 67 & 7 & 69 & 5 \\
\hline $\begin{array}{l}\text { Community } \\
\text { adaptability }\end{array}$ & 83 & 1 & 78 & 3 & 100 & 1 & 67 & 7 & 80 & 3 \\
\hline $\begin{array}{l}\text { Collaboration } \\
\text { and engagement }\end{array}$ & 58 & 9 & 44 & 12 & 67 & 7 & 75 & 4 & 59 & 9 \\
\hline $\begin{array}{l}\text { Community } \\
\text { cohesion }\end{array}$ & 75 & 2 & 78 & 3 & 89 & 5 & 83 & 2 & 80 & 3 \\
\hline $\begin{array}{l}\text { Social welfare } \\
\text { improvement }\end{array}$ & 58 & 9 & 44 & 12 & 100 & 1 & 75 & 4 & 65 & 6 \\
\hline Leadership & 58 & 9 & 50 & 11 & 56 & 9 & 25 & 15 & 47 & 12 \\
\hline Responsibility & 42 & 13 & 56 & 10 & 44 & 12 & 58 & 10 & 51 & 11 \\
\hline Altruism & 33 & 14 & 39 & 14 & 89 & 5 & 75 & 4 & 55 & 10 \\
\hline $\begin{array}{l}\text { Personal } \\
\text { Achievement }\end{array}$ & 17 & 15 & 78 & 3 & 0 & 16 & 33 & 14 & 39 & 13 \\
\hline $\begin{array}{l}\text { Business } \\
\text { development }\end{array}$ & 75 & 2 & 83 & 2 & 22 & 13 & 58 & 10 & 65 & 6 \\
\hline $\begin{array}{l}\text { Knowledge } \\
\text { improvement }\end{array}$ & 17 & 15 & 61 & 8 & 22 & 13 & 42 & 12 & 39 & 13 \\
\hline
\end{tabular}




\section{Stakeholder value priorities across different sectors}

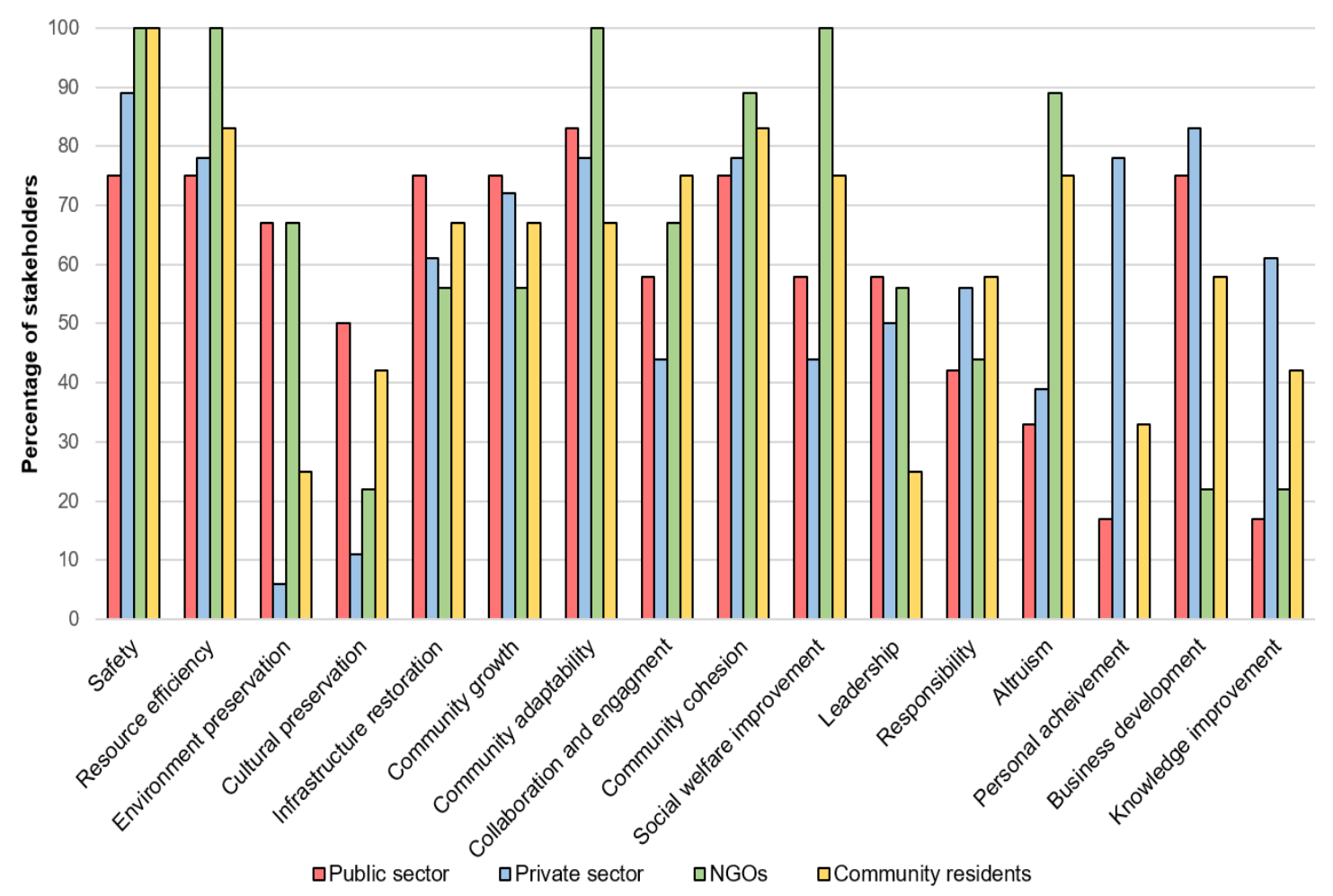

Figure 11: Stakeholder value priorities across different sectors

For example, based on to the number of interviews who mentioned the value, environmental preservation and community adaptability were ranked much higher by stakeholders from the public sector and NGOs. This is probably because Environmental preservation can encourage economic health, influence property values, and spur revenue from recreational and tourism activities. It is indeed closely linked to community adaptation as it can play a critical role in community's ability to prevent, cope with and recover from disasters and to mitigate further disaster damages. There is a growing consensus around linking disaster risk reduction with natural resource protection. The Hyogo Framework for Action (HFA) calls for efforts to "encourage the sustainable use and management of ecosystems, including through better land-use planning and development 
activities to reduce risk and vulnerabilities" (UNEP 2019, p.3). It facilitates the implementation of integrated environmental and natural resource management approaches that incorporate disaster risk reduction, such as integrated flood management and appropriate management of fragile ecosystems (UNEP 2019). An interviewee from the public sector highlighted "while large-scale disasters like Hurricane Michael cannot be entirely avoided, there are ways we can mitigate the devastating impact of disasters through better ecosystem management." Strategically planning for green space and vegetated land and restoring large swaths of natural resources (e.g., wetlands) can reduce the effects of disasters. Vegetated land absorbs water, retains it, and slows its movement, thus reducing the flooding and its subsequent effects. Planning that incorporates these features not only helps reduce flooding but also helps mitigate broader storm impacts. Similarly, in coastal regions, coral reef systems act as physical barriers and reduce wind and wave energy, thus reducing the impact of hurricanes. In Mexico Beach, the Mexico Beach Artificial Reef Association initiated one of the most active artificial reef programs in Florida. Since 1997, the organization has built over 300 patch reefs off the sandy shores of Bay and Gulf counties (Cox 2019). Without the protection provided by natural resources and ecosystems, the detrimental effects of disasters could become more catastrophic.

Social welfare improvement, on the other hand, is a value that is mostly highlighted by the community residents and NGOs. The regions struck by Hurricane Michael - both the coastal counties under an evacuation order and inland counties people fled to - are among the most socially vulnerable regions in the United States (Direct Relief 2018). Disasters like Hurricane Michael have had a huge impact on disadvantaged or vulnerable groups (e.g., economically disadvantaged, the elderly, the homeless). The economically 
disadvantaged are particularly exposed to natural disasters and they have limited access to risk management instruments. Research studies show that the poor households are less able to cope with disasters than the rich households (Vakis 2006; Vakis et al. 2004). Similarly, people who are elderly or disabled, who have mobility impairments or require special medical assistance, lack transportation or do not understand English are the most vulnerable to disasters, and they may require additional help and resources to recover. In addition, many coastal communities are particularly vulnerable during Hurricane Michael (Millis 2018). Those impacted regions have limited infrastructure and little coastal protection. Some areas in the Panhandle, such as Destin and Panama City, have dense development behind the beachfront homes, condos, and hotels, and there are bays and inlets that can easily dump water into the nearby neighborhoods. Most sections of the major highway - US-98 - in the affected communities are only 100 feet away from the coast. If the storm surge damaged one section of the highway, it would be extremely challenging for the emergency responders to reach the residents in need. Hence, in preparation for the hurricane, those coastal communities encouraged residents to take shelter in the community's central schools. One of the school principals who was interviewed mentioned that his school property was used as shelter for the homeless people during Hurricane Michael. He also emphasized that there was a need to build more emergency shelters for people who are vulnerable in the disasters. He believed that incentives and funding provided by the government would facilitate these practices, and there should be more collaboration efforts across public sector, private agencies, and NGOs.

Some values, such as personal achievement and business development, were mostly prioritized by private stakeholders. For example, business development was one of the 
highest priorities to private sector stakeholders including many small business owners in the Florida Panhandle region. Due to the impact of Hurricane Michael, many local businesses suffered from severe property structure damage and water, power, phone services outages. As one interviewee from the private sector said, "we were fortunate enough to have generators and so we were able to get power going right away. However, internet signal and cellular phone signals were not available. It took a month to get back to normal situation after the disaster." Although most small businesses purchased the insurance to cover the direct damage (e.g., structure and inventory damage), a considerable number of small companies did not have the small business interruption insurance, which could partially cover the indirect damage such as the loss of customers and revenues due to prolonged closing period. "Some businesses may never return," said an interviewee who owns a hotel. Furthermore, the interviewees expressed concerns on the employment rate. Hundreds of people could be out of work due to the impact of Hurricane Michael on the local businesses. Thirty percent of the jobs in the Panama City area are linked with the service and tourism industry, which are severely impacted by the hurricane. It is important to note, however, that the construction industry is booming in the aftermath of Hurricane Michael. Many companies have reported labor and resource shortage due to the overwhelming number of reconstruction projects. Several interviewees from the construction industry said that although their houses were damaged, they felt "blessed" that they did not lose their jobs. 


\subsection{Stakeholder Value Dynamics: Comparison Across Disaster Phases}

Stakeholder value priorities are not static, and they dynamically change across different phases of a disaster. Fig. 12 shows the dynamics of stakeholder values by plotting the numbers of interviewees who mentioned the identified values across different phases of Hurricane Michael, including disaster preparedness, response, recovery, and mitigation. For example, the top three values emphasized during the preparedness phase are safety, resource efficiency and business development whereas during the mitigation phase the top three prioritized values are community cohesion, community adaptability and community growth.

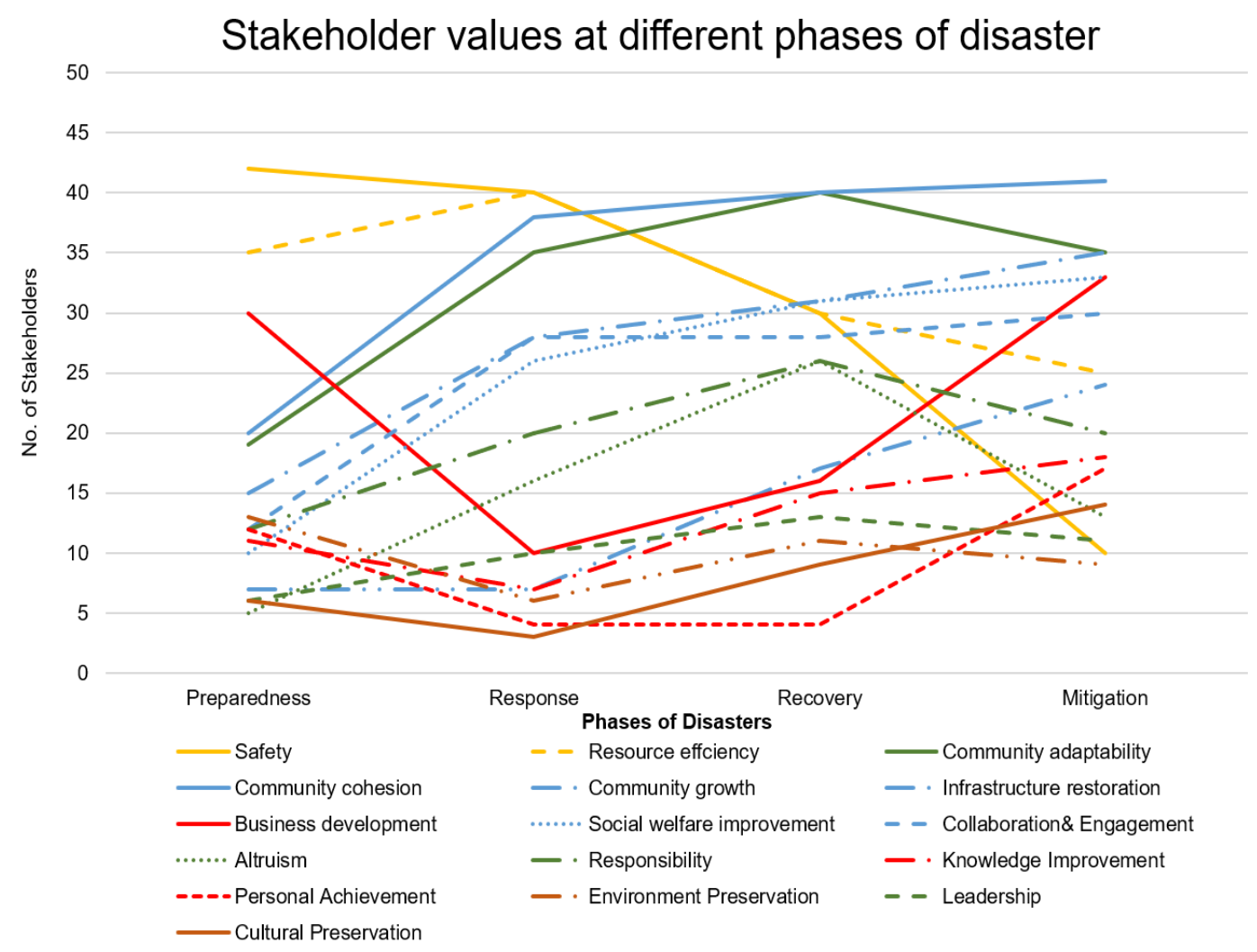

Figure 12: Stakeholder value dynamics in Hurricane Michael

As per Fig. 12, the numbers of interviewees who emphasized the importance of safety and resource efficiency gradually decrease throughout the disaster management 
cycle (i.e., from disaster preparedness to mitigation). This indicates that, in general, stakeholders have attached less importance on safety and resource efficiency soon after Hurricane Michael passed. For example, safety was emphasized by almost all stakeholders when they discussed about their value priorities in the preparedness and response phases. The rapid intensification of Hurricane Michael left little time for the local communities to get well prepared and learn about safety precautions for the disaster. Many local residents decided to shelter in place as Hurricane Michael quickly intensified from category two to category five in less than 24 hours. In the immediate aftermath of Hurricane Michael, some communities faced with houses and infrastructure completely smashed by storm surge and strong winds and weeks of power losses. Thus, ensuring the family and property safety was the main theme throughout the preparedness and response phases. During recovery and mitigation phases, the priority on safety gradually declines in part because there were no longer risks to stakeholder's lives and property. For resource efficiency, the tendency of declining is milder comparing to safety. This is probably because, during recovery and mitigation phases, interviewees from private sector and NGO raised an important concern related to resource efficiency: the construction material and labor shortage. The effort to rebuild many of the damaged communities is hampered by a severe labor shortage in the construction industry. According to a survey conducted by Association of General Contractors of America, 80 percent of the construction firms are unable to find the labor they require (AGCA 2018). As a result, homes that used to take three to four months to rebuild now take six to eight months. "We need to reach out to high school kids to spread the information and provide training," said one interviewee from a representative of construction industry. He continued, "we need to build the positive image of construction 
industry and bring more labor." Another interviewee from a local church highlighted that "having a plan for [construction] resource supply in emergent situation is crucial."

As per Fig. 12, the number of interviewees who emphasized the importance of community cohesion, collaboration and engagement, social welfare improvement, community growth and infrastructure restoration gradually increase after Hurricane Michael. The results on community cohesion, collaboration and welfare improvement are supported by a number of studies (e.g., von Dawans et al. 2012, von Dawans et al. 2018) that suggest acute stress (e.g., disaster) may lead to greater cooperative, social, and friendly behavior. Such positive and social response could help explain the human connection that happens during disasters. This human connection is responsible for and critical for the collective survival and potential improvement of the communities. Community cohesion and connection is a fundamental human need linked to both psychological and physical health in the context of disasters. It may be particularly important in a disaster setting because disasters naturally lead to a sense of vulnerability and loss of control. The feeling of vulnerability and lack of control may have led people to seek comfort of others in multiple ways (Maguire and Hagan 2007). In addition, individuals who are involved in disasters are more willing to be friendly, generous, helpful, and contribute to the community, and they realize the importance of cooperation and collaboration in achieving a common goal, which could be the overall resilience of the community (Mannakkara and Wilkinson 2013).

Fig. 12 also shows that the number of interviewees who emphasized the importance of community adaptability, altruism, responsibility and leadership gradually increase to the maximum during the recovery phase. Disaster recovery and reconstruction is a long and 
complex process that demands united efforts across multi-sector stakeholders. Successful recovery requires a sense of responsibility by public sector leaders, volunteers, and residents and adaptation to the institutional, cultural, environmental and social context within which recovery takes place. For example, regarding leadership, a public sector interviewee mentioned, "disaster relief is a complex process, but it would be simpler if you have the right people manage it in the right way". This requires the leaders not only to possess technical knowledge and soft skills but also actively engage with the affected populations. He continued, "more than often, the people just want to see that you are there for them." As an important act that reflects altruism value, volunteering activities also play an important role in facilitating the recovery process. Although many volunteers helped provide immediate disaster relief in the response phase of Hurricane Michael, it has been challenging to connect volunteers or charity to the impacted communities with resources to plan, coordinate, support, and finance the long-term recovery. Thus, several interviewees from the NGOs have emphasized the importance of strengthening the value of altruism during the recovery phase. "Things begin to calm down in the recovery phase, so this should be the time for us to replenish ourselves and have more people join our team," said an interviewee from a local volunteer group. The act of volunteering not only allows individuals to have a feeling of accomplishment but also supports the whole community by building social connections.

According to Fig. 12, the number of interviewees who mentioned business development, personal achievement, knowledge improvement, cultural preservation, and environmental preservation dropped to the bottom in the response phase. Three of these values (i.e., business development, personal achievement, knowledge improvement) 
belong to the category of self-enhancement, which emphasizes the pursuit of one's own interests and success. This result, thus, shows that people are less self-concerned in a disaster setting. Several interviewees explained that the priority of values such as safety, community cohesion, and community adaptability transcended their personal interests or success in a disaster setting, even though these self-enhancement values are prioritized more in a normal context. The affected populations are less concerned about self enhancement in a disaster setting, probably because stress and distress caused by disasters force people to focus more on social bonding and safety rather than personal wealth, power, and prestige (Albrecht 2011). Whereas research (e.g., Taylor and Sherman 2014) also shows that self-enhancement is very dynamic, it has positive illusions in a normal context as it helps manage challenging events, encourages adaptive behavior and supports wellbeing.

Similarly, the priorities on cultural and environmental preservation dropped to the bottom at the response phase while increasing importance in the other phases. For example, cultural preservation was at the minimum during the response phase, but it steadily grew in recovery and mitigation phases. Building a resilient community includes the preservation of historic and cultural resources in the short- and long-term recovery, and future mitigation efforts (NIST 2017). As highlighted by the United Nations Educational, Scientific and Cultural Organization (UNESCO), "the symbolism inherent in heritage is a powerful means to help victims recover from the psychological impact of disasters. In such situations, people search desperately for identity and self-esteem", and they find it in restoring their heritage and historic places. Heritage contributes to social cohesion, sustainable development, and psychological well-being. Protecting heritage is an essential 
way to promote community resilience (UNESCO 2015). Hurricane Michael seriously damaged and completely destroyed many historical structures (e.g., the Old Callaway School, the Judge Sapp House) in Panama City and Mexico Beach (Breaux 2019). A city commissioner emphasized the need "to preserve and maintain the historic sites of the towns and preserve the landscape of the cities". During the recovery phase, following the guidance on protecting heritage and the treatment of historic areas and individual historical buildings, he strived to work with landscape planners and architects to restore the historic districts of urban areas. "It is a challenging process," said the city commissioner, "we need to balance the life safety, economic value, and preservation values in long-term recovery and planning." The key is to retain historic features while sensitively incorporating new features that reduce the risk of future damage from the disasters. 


\section{RECOMMENDATIONS FOR IMPROVING DISASTER RESILIENCE OF COMMUNITIES}

Based on the results of the interviews, some possible actions to enhance disaster resilience of communities at the Florida Panhandle region are as follows:

(1) Prioritize the implementation of disaster management practices based on stakeholder value priorities: The results of the interview indicate that although the ranks of the values were different based on different stakeholders' perspectives, these is a general consensus on the importance of the identified values; stakeholders consistently attach higher importance to certain values (e.g., safety, resource efficiency). There is, thus, a need to prioritize the implementation of disaster management practices based on stakeholder value priorities. In Florida Panhandle area, many local communities are still not investing enough in supporting disaster resilience policies or practices, and many decision makers have not yet prioritized enough support to improve disaster resilience. Given limited resources, future efforts should be spent on the policies or practices that can best fulfill stakeholder values. To offer higher benefits and satisfaction to community stakeholders, resilience planning should be conducted in a way that is aligned with stakeholder value priorities. For example, policy makers can offer additional training or education sessions to their workforce, NGO personnel, and interested residents on planning for, allocating, and utilizing resources more efficiently in prior to and after disasters, since resource efficiency was considered as one of the most prioritized values by these stakeholders. These valuedriven practices can be integrated into community development plans in order to prioritize the implementation of disaster resilience strategies within the community budget.

(2) Tailor disaster management practices to different stakeholders' value priorities: The 
results of the interview show that some values were ranked differently by different sectors of stakeholders. Given such difference, there is a need to tailor disaster management policies or practices to different stakeholders' value priorities. Instead of a universally applied disaster management/resilience plan, some practices or guidelines can be developed through consultation and coordination with the relevant stakeholders given their specific needs, resources, and expectations. Although some stakeholders, such as private stakeholders and community residents, are not typically involved in disaster management processes, they are directly impacted by disasters, and they also possess additional resources and knowledge that can be used to support disaster management. Therefore, their values in a disaster context, though sometimes different than the values of the public stakeholders, should be taken into consideration when disaster management decisions are being made. For example, given social welfare improvement is heavily emphasized by community residents, our decision makers can prioritize actions or allocate more resources to identify vulnerable populations in a disaster and offer specialized support to address the needs, concerns, and risks to these populations.

(3) Customize disaster management practices across different phases of disasters based on

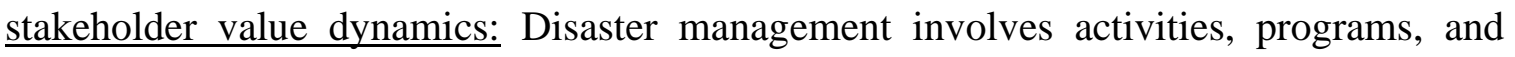
measures that are implemented based on the disaster management cycle - i.e., disaster preparedness, response, recovery, and mitigation phases. According to the results of our study, stakeholder value systems are not static in the context of a disaster; it dynamically changes throughout different phases of a disaster. For example, a community resident who considered safety as the top priority during the preparedness phase changed to attach the highest importance to community adaptability during the mitigation phase. Thus, decision 
makers or policymakers should customize the implementation of disaster management practices based on stakeholder value dynamics and ensure that the right practices are implemented at the right time. For example, policy makers can build on post-disaster community cohesion for implementing new resilience policies regarding sea level rise in coastal communities, given that the value priority towards community adaptability (e.g., adapt to climate change, sea level rise) becomes relatively higher in this phase.

(4) Integrate and unite the value systems of multi-sector stakeholders: Disaster management is a shared responsibility among all stakeholders, which requires collaboration and engagement of multi-sector stakeholders. Thus, to build more resilient communities, it is important to understand and integrate the values of all these stakeholders. Different stakeholders have different value priorities in a disaster context. The differences in the value systems of these stakeholders motivate them to make different judgment, evaluation, or decisions, lead to conflicts and disputes, and result in longer decision-making time and potentially millions of dollar losses in the future. Thus, more systematic and formal integration and unification of stakeholder's diverse value systems is sorely needed. Such integration will facilitate more resilient communities by contributing to (1) fewer conflicts and disputes among multi-sector stakeholders in disaster management processes, (2) shorter time and money-saving for decision making, (3) more transparency and consistency, and most importantly (3) higher level of satisfaction and greater collective value delivered to multi-sector stakeholders. 


\section{CONCLUSIONS, CONTRIBUTIONS, AND FUTURE WORK}

This thesis presents a study on identifying and understanding multi-sector stakeholder values in the context of Hurricane Michael. A total of 41 interviews were conducted with 51 interviewees from the public and private sectors, NGOs, and community residents of the impacted communities in the Florida Panhandle area. Based on the interview results, sixteen values were identified and analyzed, including safety, resource efficiency, environmental preservation, cultural preservation, infrastructure restoration, community growth, community adaptability, collaboration and engagement, community cohesion, social welfare improvement, leadership, responsibility, altruism, personal achievement, knowledge improvement and business development. These values were then classified into conservation, openness to change, self-transcendence, and self-enhancement categories based on Schwartz's (2012) Theory of Basic Human Values. The priorities of values were further analyzed based on the number of interviewees who mentioned these values during their interviews. Safety, recourse efficiency, community cohesion, and community growth were among the most prioritized values based on stakeholders' opinions. Although there is a general consensus on the importance of the identified values, the ranks of these values were different based on different stakeholders' perspectives. In addition, the dynamics of stakeholder values were analyzed by investigating how their importance changes throughout different phases of Hurricane Michael. The results show that different values have different changing patterns. For example, the priorities of safety and resource efficiency gradually decrease throughout the disaster phases, while the priorities of community growth, community cohesion, social welfare improvement, collaboration and engagement, and infrastructure restoration show a steady growth. 
This research contributes to the body of knowledge on disasters in three primary ways. First, it provides important knowledge on the interactions between the human element and built environment by explicitly identifying and defining what stakeholders value in community disaster resilience. Second, it offers a critical understanding on the priorities, consistency, and differences among multi-sector stakeholders in achieving disaster resilience of the communities, which could facilitate stakeholder engagement and collaboration in building more resilient communities. Third, it advances the knowledge on human value theory by investigating how natural disasters impact multi-sector stakeholder value systems, which are fundamental to timely and human-centered decision making during the preparedness, response and recovery phases of disasters.

This thesis indicates several directions for future research. First, there is a need for studies on stakeholder values that will be based on stakeholder surveys involving a larger number of stakeholders. These surveys can focus on understanding the value priorities of multi-sector stakeholders in a quantitative manner across different disasters. Analysis can be conducted to understand and compare the value priorities and their dynamics of stakeholders with different demographic and socioeconomic backgrounds. For further research, different types of data can be collected and analyzed. For example, study and analysis can be conducted based on secondary sources of data, such as news articles, social media data, emergency management and other public department reports. Second, more analysis and comparative studies that focus on different types of communities, and/or across different sublevel sectors (e.g., different sectors of public agency, different businesses or industries) and different disaster events, can be conducted. For example, comparative studies can be conducted between the stakeholder values of rural communities 
and urban communities, or between different types of vulnerable populations. Third, further studies can be conducted to identify and analyze more stakeholder values apart from the 16 stakeholder values identified and discussed in this thesis. Fourth, future studies can use social network analyses to understand if stakeholders' value priorities are affected by other stakeholders. Fifth, there is a need for developing mathematical models that further unite or aggregate the value priorities of multi-sector stakeholders while accounting for the influences among these stakeholders. 


\section{REFERENCES}

Adekola, J., Fischabcher-Smith, D. \& Fischabcher-Smith, M. (2020). "Inherent Complexities of a Multi-stakeholder Approach to Building Community Resilience.” International Journal of Disaster Risk Science, 11, 32-45.

AGCA (Associated General Contractors of America). (2018). "Eighty percent of contractors report difficulty finding qualified craft workers to hire as association calls for measures to rebuild workforce". Accessed Feb 20, 2019. https://www.agc.org/news/2018/08/29/eighty-percent-contractors-reportdifficulty-finding-qualified-craft-workers-hire- 0 .

Albrecht, G. (2011) "Chronic Environmental Change: Emerging 'Psychoterratic' Syndromes." In: Weissbecker I. (eds) Climate Change and Human Well-Being. International and Cultural Psychology. Springer, New York, NY.

Allport, G. W, Vernon, P. Ewart, \& Lindzey, G. (1960). "Study of values. Manual : A scale for measuring the dominant interests in personality." 3rd ed. Boston: Houghton Mifflin.

Ariza-Montes, A., Arjona-Fuentes, J. M., Han, H., \& Law, R. (2017). "Employee responsibility and basic human values in the hospitality sector." International Journal of Hospitality Management, 62, 78-87.

Bannour, W., Maalel, A. \& Ben G. H. (2018). "Towards a collaborative method for crisis management."

Bardo, J. (1978). "Organizational Response to Disaster: a Typology of Adaptation and Change." Mass Emergencies 3(September), 87-104.

Bardi, A., Buchanan, K.E., Goodwin, R., Slabu, L., and Robinson, M. (2014). "Value stability and change during self-chosen life transitions: self-selection versus socialization effects." Journal of Personality and Social Psychology, 106, 131-147.

Barton, A. H. (1969). "Communities in Disaster: A Sociological Analysis of Collective Stress Situations." Garden City, NY: Doubleday and Company Inc.

Breaux, C. (2019). "5 historic Bay County sites after Hurricane Michael.” Accessed Feb 1, 2019. https://www.newsherald.com/news/20190104/5-historic-bay-county-sitesafter-hurricane-michael.

Chang, K. (2010). "Community cohesion after a natural disaster: Insights from a Carlisle flood." Disasters, 34 (2), 289-302.

Cheng, A., and Fleischmann, K. (2010). "Developing a meta-inventory of human values." Proc.,American Society for Information Science and Technology (ASIST 2010), 47 (3), Pittsburgh, PA, USA. 
Choi, S. O., and Brower, R. S. (2006). "When practice matters more than government plans a network analysis of local emergency management." Administration and Society, $37(6), 651-678$.

Chhotray, V., and Few, R. (2012). "Post-disaster Recovery and Ongoing Vulnerability: Ten Years after the Super-Cyclone of 1999 in Orissa, India." Global Environmental Change, 22(3), 695-702.

Choi, S. O., and Kim, B. T. (2007). "Power and cognitive accuracy in local emergency management networks." Public Administration Review, 67(s1), 198-209.

Chow, D. (2018). "Conditions were ripe for Hurricane Michael's 'rapid intensification"” Accessed Mar 1, 2019. https://www.nbcnews.com/mach/science/conditions-wereripe-hurricane-michael-s-rapid-intensification-ncna918711.

Cohen, A. (2009). "Individual values and the work/family interface: An examination of high tech employees in Israel," Journal of Managerial Psychology, 24(8), 814-832.

Cohen, A., \& Shamai, O. (2010). "The relationship between individual values, psychological well-being, and organizational commitment among Israeli police officers," Policing: An International Journal of Police Strategies \& Management, 33(1), 30-51.

Cox, C. (2019). "Hurricane Michael, where did you put our reefs?” Accessed Feb 19, 2019. https://www.starfl.com/news/20190228/hurricane-michael-where-did-you-putour-reefs.

Daniel, E., Fortuna, K., Thrun, S. K., Cioban, S., and Knafo, A. (2013). "Early adolescents' value development at war time. ” Journal of Adolescence, 36, 651-655.

DirectRelief. (2018). "Hurricane Michael Strikes Some of the Nation's Most Vulnerable Communities." Accessed $\quad$ Feb 2019. https://www.directrelief.org/2018/10/hurricane-michael-strikes-some-of-thenations-most-vulnerable-communities/.

Drabek, T. E. and McEntire, D.A. (2003). "Emergent Phenomena and the Sociology of Disaster: Lessons, Trends and Opportunities from the Research Literature." Disaster Prevention and Management 12(2), 97-112.

Emmanuel R. (2013). "Exploring Disaster Recovery Coordination: Stakeholder Interfaces, Goals and Interdependencies."

FEMA (Federal Emergency Management Agency). (2018). 2017 Hurricane Season FEMA After-Action Report, FEMA, Maryland, MA.

Fischer, R. (2017). “Personality, Values, Culture.” Cambridge: Cambridge University 
Frederickson, D. G. and Frederickson, H. G. (2006). Measuring the performance of the hollow state. Georgetown University Press, Washington, DC.

Fritz, C., and Mathewson, J. (1957). Convergence Behavior in Disasters (National Research Council Disaster Study \#9). National Academy of Sciences, Washington D.C.

Ganapati, N. E., and Mukherji, A. (2014). "Out of sync: World Bank funding for housing recovery, post-disaster planning and participation." Natural Hazards Review, 15 (1), 58-73.

Ganapati, N. E., and Ganapati, S. (2009). "Enabling participatory planning in post-disaster contexts: a case study of World Bank's housing reconstruction in Turkey." Journal of the American Planning Association, 75 (1), 41-59.

Ganapati, N. E., (2009). "Rising from the Rubble: Emergence of Place-Based Social Capital in Gölcük, Turkey". International Journal of Mass Emergencies and Disasters, 27 (2), 127-166. Goodman, L.A. (1961). "Snowball sampling." Annuals of Mathematical Statistics, 32 (1), 148-170.

Giménez, A.C., \& Tamajón, L.G. (2019). Analysis of the third-order structuring of Shalom Schwartz's theory of basic human values. Heliyon.

Gouveia, V. V. (2013). "Functional theory of Human Values: Fundaments, Applications and Perspectives." São Paulo: Casa do Psicólogo.

Guo, X., and Kapucu, N. (2015). "Network performance assessment for collaborative disaster response." Disaster Prevention and Management, 24(2), 201-220.

Hitlin, S., and Piliavin, J. (2004). "Values: reviving a dormant concept." Annual Review of Sociology, 30 , 359-393.

Hostmann, M., Borsuk, M., Reichert, P., and Truffer, B. (2005). "Stakeholder values in decision support for river rehabilitation." Large Rivers, 15 (1-4), 491-505.

Hu, Q., Knox, C. C., and Kapucu, N. (2014). "What have we learned since September 11, 2001? A network study of the Boston marathon bombings response." Public Administration Review, 74(6), 698-712.

Jehn, K. A. (1994). "Enhancing effectiveness: an investigation of advantages and disadvantages of value-based intragroup conflict." International journal of conflict management, 5(3), 223-238.

Kapucu, N., and Garayev, V. (2011). "Collaborative decision-making in emergency and disaster management." International Journal of Public Administration, 34 (6), 366375. 
Kapucu, N., and Van Wart, M. (2006). "The emerging role of the public sector in managing extreme events: lessons learned.” Administration and Society, 38 (3), 279-308.

Keeney, R.L. (1992). Value-focused thinking - a path to creative decision making. Harvard University Press, Cambridge, MA.

LaLone, M. B. (2012). "Neighbors Helping Neighbors: An Examination of the Social Capital Mobilization Process for Community Resilience to Environmental Disasters.” Journal of Applied Social Science, 6 (2), 209-237, Virginia, USA.

Lindell M.K., Prater C.S. \& Peacock W.G. (2007). "Organizational Communication and Decision Making for Hurricane Emergencies." Natural Hazard review, 8(3).Lönnqvist, J.-E., Jasinskaja-Lahti, I., and Verkasalo, M. (2013). "Rebound effect in personal values: Ingrian Finnish migrants' values two years after migration." Journal of Cross-Cultural Psychology, 44, 1122-1126.

Lynam, T., W. De Jong, D. Sheil, T. Kusumanto, and K. Evans. (2007). “A review of tools for incorporating community knowledge, preferences, and values into decision making in natural resources management." Ecology and Society, 12(1), 5.

Lyons, S. T., Duxbury, L. E., \& Higgins, C. A. (2006). "A comparison of the values and commitment of private sector, public sector, and parapublic sector employees," Public administration review, 66(4), 605-618.

Maguire, B. and Hagan, P. (2007). "Disasters and Communities: Understanding Social Resilience.” Australian Journal of Emergency Management, 22(2), 16-20.

Mannakkara, S and Wilkinson, S. (2013). "Build Back Better principles for post-disaster structural improvements." Structural Survey, 31(4).

Millis, R. (2018). “These are some of Florida's most vulnerable areas. And they're right in the path of Hurricane Michael." Accessed Feb 22, 2019. https://www.usatoday.com/story /news/nation-now/2018/10/09/hurricanemichael-targets-florida-poor-vulnerable-coastal-regions/1575641002/.

Milward, H. B., and Provan, K. G. (2000). "Governing the hollow state.” Journal of Public Administration Research and Theory, 10(2), 359-380.

Mojtahedi M. \& Bee Lan Oo. (2017). "The impact of stakeholder attributes on performance of disaster recovery projects: The case of transport infrastructure." International Journal of Project Management, 35(5).

National Weather Service. (2018). "Storm Data and Unusual Weather Phenomena."

Accessed Feb 10, 2019. https://www.google.com/url?sa=t\&source=web\&rct=j\&url=https: //www.weather.gov/media/bmx/stormdat/2018/bmxoct2018.pdf\&ved=2ahUKEwj U0buo2- 
jgAhXkx1kKHXQPD6w4ChAWMAJ6BAgCEAE\&usg=AOvVaw1jAjlEtZ9WKpu89f2nx23.

NIST. (2017). "WBDG - Whole Building Design Guide.” Accessed Feb 22, 2019. https://www.wbdg.org/design-objectives/historic-preservation.

NOAA (National Oceanic and Atmospheric Administration). (2018). "Destructive 2018 Atlantic hurricane season draws to an end." Accessed on Oct 1,2019. https://www.noaa.gov/media-release/destructive-2018-atlantic-hurricane-seasondraws-to-end.

Parr, A. (1970). "Organizational Response to Community Crises and Group Emergence." American Behavioral Scientist 13(3), 423-429.

Perryman, D. R. (2018). "The Perryman group - An Economic and Financial Anaylsis Firm." Accessed Feb 02, 2019. https://www.perrymangroup.com/hurricanemichael.

Plough, A., Fielding,J.E., Chandra, A., Williams, M., Eisenman, D., Wells, K.B., Law,G.Y., Fogleman S., and Magana, A. (2013). "Building Community Disaster Resilience: Perspectives From a Large Urban County Department of Public Health." Promoting Public Health Research, Policy, Practice and Education, 103 (7), 1190-1197.

Räikkönen, M.; Molarius, R.; Mäki, K.; Forssén, K.; Petiet, P.; Nieuwenhuijs, A. (2017). "Creating Stakeholder Value through Risk Mitigation Measures in the Context of Disaster Management." Infrastructures, 2 (14).

Reeves, J., and Lush, T. (2018). "Hurricane Michael wipes out Mexico Beach, Florida, in 'apocalyptic' assault.” Accessed Feb 16, $2019 . \quad$ https://www.sunsentinel.com/news/ weather/hurricane/fl-ne-hurricane-michael-apocalypse20181011-story.html.

Rhodes, R. A. (1994). "The hollowing out of the state: The changing nature of the public service in Britain." The Political Quarterly, 65(2), 138-151.

Rokeach, M. (1971). "Long-range experimental modification of values, attitudes, and behavior." American Psychologist, 26(5), 453-459.

Rudnev, M. (2014). "Value adaptation among Intra-European migrants: role of country of birth and country of residence." Journal of Cross-Cultural Psychology, 45, 16261642.

Schwartz, S. H., \& Bilsky, W. (1990). "Toward a theory of the universal content and structure of values: Extensions and cross-cultural replications." Journal of Personality and Social Psychology, 58(5), 878-891. 
Schwartz, S. H. (1992). "Universals in the content and structure of values: Theoretical advances and empirical tests in 20 countries, " Advances in Experimental Social Psychology, Vol. 25.

Schwartz, S. (2004). "Human values: European social survey education net." Accessed Feb 05, 2019. http://essedunet.nsd.uib.no/cms/topics/1/.

Schwartz, S. (2012). "An overview of the Schwartz theory of basic values". Online reading in Psychology and Culture, 2 (1).

Schwartz, S. (2014). "Functional theories of human values: Comment on Gouveia, Milfont, and Guerra (2014).” Personality and Individual Differences, 68, 247-249.

Singer, E., and Couper, M. (2017). Some Methodological Uses of Responses to Open Questions and Other Verbatim Comments in Quantitative Surveys. methods, data, analyses, 11(2), 20.

Spranger, E. (1921). "Types of men: Humanistic Psychology and Ethic of the Personality."

Subramaniam, C. \& Ali, H., Mohd-Shamsudin, F. (2010). "Understanding the antecedents of emergency response: A proposed framework." Disaster Prevention and Management. 19. 571-581.

Taylor, S.E., and Sherman, D.K. (2014). "Self-enhancement and Self-affirmation: The Consequences of Positive Self-thoughts for Motivation and Health." In W. Gardner and J. Shah (Eds.) Handbook of Motivation Science (pp. 57-70), The Guilford Press, New York, NY.

Tantalo, C., and Priem, R. L. (2016). "Value creation through stakeholder synergy." Strat. Mgmt. Journal, 37, 314-329.

Tompson, T., Benz, J., Agiesta, J., Cagney, K., and Meit, M. (2013). "Resilience in the Wake of Superstorm Sandy." The Associated Press and NORC-Center for Public Affairs Research, Accessed Feb 20, 2019. http://www.apnorc.org/projects/Pages/resilience-in-the-wake-of-superstormsandy.aspx.

Tormos, R., Vauclair, C.M., and Dobewall, H. (2017). "Does contextual change affect basic human values? A dynamic comparative multilevel analysis across 32 European countries." Journal of Cross-Cultural Psychology,48 (4), 490-510.

Townshend, I., Awosoga, O., Kulig, J., and Fan, H. (2015). "Social cohesion and resilience across communities that have experienced a disaster." Spring Link-Natural Hazards, 76 (2), 919-938. 
UNEP. (2019). “UNEP-Environmental-Management-for-DRR.” Accessed Feb 20, 2019. https://www.preventionweb.net/english/hyogo/gar/background-papers/documents /Chap5/thematic-progress-reviews/.

UNESCO (United Nations Educational, Scientific and Cultural Organization). (2015). Revisiting Kathmandu: safeguarding living urban heritage. UNESCO, Paris, France.

Vakis, R., Kruger, D., and Mason, A.D. (2004) "Shocks and Coffee: Lessons from Nicaragua." Social Protection Discussion Paper No. 0415, The World Bank, Washington, DC.

Vakis, R. (2006). "Complementing Natural Disasters Management:The Role of Social Protection." Social Protection Discussion Paper No. 0543, The World Bank, Washington, DC.

Verkasalo, M., Goodwin, R., and Bezmenova, I. (2006). "Value change following a major terrorist incident: Finish adolescent and student values before and after 11th September 2001." Journal of Applied Social Psychology, 36, 144-160.

von Dawans, B., Fischbacher, U., Kirschbaum, C., Fehr, E., and Heinrichs, M. (2012) “The Social Dimension of Stress Reactivity : Acute Stress Increases Prosocial Behavior in Humans." Psychological Science - Sage Journals, 23(6), 651-660.

von Dawans, B., Trueg, A., Kirschbaum, C., Fischbacher, U., and Heinrichs, M. (2018). "Acute social and physical stress interact to influence social behavior: The role of social anxiety." PloS one, 13(10).

Zhang, L. and El-Gohary, N.M. (2016). "Discovering stakeholder values for axiologybased value analysis of building projects." Journal of Construction Engineering and Management, 142(4), 4015095-1-4015095-15.

Zubir, A., Thiruchelvam, S., Mustapha, K., Che M., Zakaria, Ghazali, A., Hakimie, H., Razak, A., Normy, Isa, Abdul, Hasini, Hasril, Sahari, K., Mat H., Norhayati, Rusli, Mohd, Muda, Rahsidi S., Mohd S., Lariyah, Basri, Hidayah, Tukiman, Izawati. (2016). "Conceptualization of a Collaborative Decision Making for Flood Disaster Management." Earth and Environmental Science. 32. 


\section{APPENDIX}

Interview Instrument

\begin{tabular}{|l|l|}
\hline Interviewer: & \\
\hline Date: & \\
\hline Place: & \\
\hline Starting Time: & \\
\hline Interviewee/Pseudonym: & \\
\hline
\end{tabular}

\section{A. COMMUNITY PRIOR TO THE HURRICANE}

With your permission, I would like to start our interview by talking about your community before Hurricane Michael.

A1. Can you please explain to me how your community was prior to the hurricane?

A2. What did you value in your community prior to Hurricane Michael?

A3. What concerned you the most about your community prior to Hurricane Michael?

A4. Please tell me more about why this concerned you the most at the time.

\section{B. PREPAREDNESS}

Now I will be asking you questions about the first few days before Hurricane Michaelafter you learned that the hurricane might be coming your way but before the hurricane landed.

B1. What did you/your group/your organization value about this community the most at that time?

B2. Can you please tell me why this mattered to you/your group/your organization the most at the time?

B3. Given that this is what you valued at the time, please tell me one thing the government (federal, state or local) should have done but did not do right before the 
hurricane.

B4. Please explain why you think doing this would have helped the community at the time.

B5. Now, please tell me one thing the government did do but should not have done or should have done differently right before the hurricane.

B6. Please explain why you think doing this did not help the community at the time.

B7. Thinking back, what do you think you/your group/your organization should have valued the most about your community at that time?

B8. Can you please tell me why this should have mattered to you/your group/your organization the most at the time?

B9. Given that this is what you should have valued at the time, please tell me one thing the government (federal, state or local) should have done but did not do right before the hurricane.

B10. Please explain why you think doing this would have helped the community at the time.

B11. Now, please tell me one thing the government did do but should not have done or should have done differently right before the hurricane.

B12. Please explain why you think doing this did not help the community at the time.

\section{RESPONSE}

Now I will be asking you questions about the immediate aftermath of Hurricane Michael. This is before you had a sense that your community started recovering from the hurricane (e.g., initial few days).

C1. What did you/your group/your organization value the most about this community 
at that time?

C2. Can you please tell me why this mattered to you/your group/your organization the most at the time?

C3. Given that this is what you valued at the time, please tell me one thing the government (federal, state or local) should have done but did not do immediately after the hurricane.

C4. Please explain why you think doing this would have helped the community at the time.

C5. Now, please tell me one thing the government did do but should not have done or should have done differently immediately after the hurricane.

C6. Please explain why you think doing this did not help the community at the time.

C7. Thinking back, what do you think you/your group/your organization should have valued the most about your community at that time?

C8. Can you please tell me why this should have mattered to you/your group/your organization the most at the time?

C9. Given that this is what you should have valued at the time, please tell me one thing the government (federal, state or local) should have done but did not do immediately after the hurricane.

C10. Please explain why you think doing this would have helped the community at the time.

C11. Now, please tell me one thing the government did do but should not have done or should have done differently immediately after the hurricane.

C12. Please explain why you think doing this did not help the community at the time. 


\section{RECOVERY}

The questions in this section relate to now-as you continue to recover from the hurricane. D1. What are the top three things that you/your group/your organization value about this community as you recover from the hurricane?

D2. Which one of these is at the top of your list?

D3. Can you please tell me why this matter to you/your group/your organization right now?

D4. Given that this is what you value, please tell me one thing the government (federal, state or local) should be doing but is currently not doing.

D5. Please explain why you think doing this would help the community as it recovers from the hurricane.

D6. Now, please tell me one thing the government is doing but should not be doing or should be doing differently right now.

D7. Please explain why you think doing this is not helping the community as it recovers from the hurricane.

D8. Let's move on to the other things you value right now. Which one would you put as the second? $[\ldots]$ or $[\ldots]$ ?

D9. Can you please tell me why this matters to you/your group/your organization right now?

D10.Given that this is what you value, please tell me one thing the government (federal, state or local) should be doing but is currently not doing.

D11.Please explain why you think doing this would help the community as it recovers from the hurricane. 
D12.Now, please tell me one thing the government is doing but should not be doing or should be doing differently right now.

D13.Please explain why you think doing this is not helping the community as it recovers from the hurricane.

D14.Now, let's talk about the last thing you value right now: [...].

D15.Can you please tell me why this matters to you/your group/your organization right now?

D16.Given that this is what you value, please tell me one thing the government (federal, state or local) should be doing but is currently not doing.

D17.Please explain why you think doing this would help the community as it recovers from the hurricane.

D18.Now, please tell me one thing the government is doing but should not be doing or should be doing differently right now.

D19.Please explain why you think doing this is not helping the community as it recovers from the hurricane.

\section{E. FUTURE OF THE COMMUNITY}

Now I will be asking you a few questions related to the future of your community.

E1. What concerns you about the future of your community?

E2. How do you envision your community ten years from now?

E3. Please tell me why you envision your community this way?

E4. What do you think needs to be done to make this vision a reality?

E5. What are the challenges that might arise as you work towards achieving your vision for the community? 
E6. What might help you towards achieving your vision for the community?

\section{F. DEMOGRAPHICS}

Please fill out the following section about your background.

F1. How old are you?
$18-25$
46-50
26-30
$51-55$
31-35
$56-60$
$36-40$
61-65
41-45
Above 65

F2. What is the highest degree of level of school you have completed? If you are currently enrolled, please mark the previous grade or highest degree received.

Less than 12th grade

12 th grade, no diploma

High school graduate- high school diploma or the equivalent (example: GED)

Some college credit, no degree
Associate degree (e.g., AA, AS

Bachelor's degree

Graduate degree

Professional degree (e.g., MD, JD)

Other (please specify)

F3. What is your ethnicity?

Hispanic or Latino $\quad \square \quad$ Not Hispanic or Latino

F4. Could you please specify your race?

American Indian or Alaska Native

Asian

White
Black or African American

Native Hawaiian or Other Pacific Islander

Do not know

F5. Please mark your gender below.

$\square \quad$ Male

Female

F6. Do you work? 

Yes
No

F7. If you do work, how long have you been working in your current workplace?

$\square$ Less than 1 year $\quad \square \quad$ More than 6 years but less

More than 1 year but less than 3 years

$\square$ More than 3 years but less than 6 years than 9 years

$\square \quad$ More than 9 years but less than 12 years

12 years or more

We are at the end of our interview. Do you have any questions for me or anything you would like to talk about that I have not asked about?

Also, if it is OK with you, I would like you to suggest a few individuals for me to contact. These individuals could be policy makers, community leaders, heads of associations or those who have been actively involved in preparedness, response and recovery of this community.

\section{THANK YOU VERY MUCH FOR YOUR PARTICIPATION}

